\title{
The Ladder of Life Detection
}

\author{
Marc Neveu,, Lindsay E. Hays, ${ }^{2,3}$ Mary A. Voytek, Michael H. New, and Mitchell D. Schulte ${ }^{2}$
}

\begin{abstract}
We describe the history and features of the Ladder of Life Detection, a tool intended to guide the design of investigations to detect microbial life within the practical constraints of robotic space missions. To build the Ladder, we have drawn from lessons learned from previous attempts at detecting life and derived criteria for a measurement (or suite of measurements) to constitute convincing evidence for indigenous life. We summarize features of life as we know it, how specific they are to life, and how they can be measured, and sort these features in a general sense based on their likelihood of indicating life. Because indigenous life is the hypothesis of last resort in interpreting life-detection measurements, we propose a small but expandable set of decision rules determining whether the abiotic hypothesis is disproved. In light of these rules, we evaluate past and upcoming attempts at life detection. The Ladder of Life Detection is not intended to endorse specific biosignatures or instruments for life-detection measurements, and is by no means a definitive, final product. It is intended as a starting point to stimulate discussion, debate, and further research on the characteristics of life, what constitutes a biosignature, and the means to measure them. Key Words: Life detection-Life-detection instruments-Biosignatures-Biomarkers. Astrobiology 18, 1375-1402.
\end{abstract}

\section{Introduction}

$\mathbf{L}$ IFE DETECTION ENCOMPASSES all measurements seeking $\Delta$ to find life, including searching for biosignatures and establishing context. Biosignature measurements directly seek features characteristic of life (such as complex organic matter not known to be formed through only chemical reactions, or concentrations of biologically necessary or useful elements) as evidence of ongoing or past biological processes. Establishing context encompasses the measurements seeking to determine the properties and processes (such as habitability or competing abiotic mechanisms) inherent both to the environment investigated and to the environments through which the sample provenance can be traced.

Plans to detect life beyond Earth materialized soon after the dawn of the space age (Lederberg, 1960; Dick, 2006). Soon after launching the first interplanetary missions, NASA formulated what would become the Viking missions to land on Mars with life-detection experiments (Ezell and Ezell, 1984; Dick, 2006). The Viking landers reached the surface of Mars in 1976 and performed a suite of carefully designed and tested experiments seeking signs of active metabolism in martian regolith samples. If taken independently, some of the measurements made during the experiments performed by Viking could be interpreted as demonstrating the presence of metabolic activity. However, taken together with a null result on a chemical measurement of life's organic building blocks, they cannot exclude the conclusion that life was absent in the Viking samples (Klein, 1978). These Viking mission experiments remain the only direct, in situ attempt to date at detecting life on another world. ${ }^{1}$

Since the 1970s, our knowledge of life on Earth has considerably improved due to advances in biological analysis (Woese et al., 1990; Hug et al., 2016), searches for the oldest evidence of life (e.g., Schopf, 1993; Mojzsis et al., 1996; Dodd et al., 2017), and serendipity (e.g., discovering thriving ecosystems based on chemolithotrophy at the dark seafloor; Corliss et al., 1979). In 1996, McKay et al. presented multiple lines of evidence for fossil life in the martian meteorite ALH84001. This claim was much debated

\footnotetext{
${ }^{1}$ Aside from quarantine analyses of lunar samples returned by Apollo 11, 12, and 14 (Meltzer, 2011).
}

\footnotetext{
${ }^{1}$ NASA Postdoctoral Management Program Fellow, Universities Space Research Association, Columbia, Maryland.

${ }^{2}$ NASA Headquarters, Washington, DC.

${ }^{3}$ Jet Propulsion Laboratory, California Institute of Technology, Pasadena, California.

(C) Marc Neveu et al., 2018; Published by Mary Ann Liebert, Inc. This Open Access article is distributed under the terms of the Creative Commons Attribution Noncommercial License (http://creativecommons.org/licenses/by-nc/4.0/) which permits any noncommercial use, distribution, and reproduction in any medium, provided the original author(s) and the source are credited.
} 
(Martel et al., 2012, and references therein), and the scientific consensus today is that the ALH84001 meteorite does not demonstrate the presence of life on Mars. However, the announcement and subsequent debate over the interpretations by McKay et al. would spur interdisciplinary efforts to bridge communities seeking to understand the emergence, workings, and extremes of life on Earth and those looking for habitats in and beyond our solar system (Dick, 2006).

The understanding of biology and planets has progressed to the point where life-detection missions are once again a high priority. The top-priority flagship Solar System mission for this decade (the Mars 2020 rover mission, now in development) is designed to gather compelling samples of Mars that could be returned to Earth by a future mission to allow scientists, using the latest laboratory equipment, to search for evidence of extinct or even extant life in these samples (National Research Council, 2011). Moreover, the United States Congress has directed NASA to "create an Ocean World Exploration Program whose primary goal is to discover extant life on another world" (H. Rept. 114-130, 2015). This resulted in the formulation of a Europa lander mission concept whose primary goal would be to search for signs of life (Hand et al., 2017). Space telescopes being built will seek nearby habitable planets and possible spectroscopic fingerprints of life in exoplanet atmospheres (National Research Council, 2010), with life detection by direct imaging awaiting larger assets currently at the planning stage (Meadows et al., 2016).

In these searches, it is crucial that we apply lessons learned from past efforts to detect life, whether remotely, in the field (in situ), or in the laboratory (on returned samples). These past efforts were challenged by a lack of contextual knowledge and by potential contamination from Earth life and its building blocks. Thus, past claims of microbial life detection in extreme environments (Priscu et al., 1999; Schrenk et al., 2003), deep time (Schopf, 1993; Mojzsis et al., 1996; Summons et al., 1999), and beyond Earth (Levin and Straat 1977; McKay et al., 1996) have been debated to this day (M.D. Brasier et al., 2002, 2015; van Zullen et al., 2002; Lepland et al., 2005; Martel et al., 2012; French et al., 2015; Levin and Straat, 2016). In one instance, the debate concerned not whether, but rather to which extent, the detected life was indigenous (Bulat et al., 2004). These challenges must be mitigated to acquire evidence that successfully convinces a majority of the scientific community that signs of indigenous life claimed to be present in the environments explored are correct.

To guide the search and help establish standards across different fields of science, we have assembled a Ladder of Life Detection. Using lessons learned from previous attempts at detecting life, we derive criteria that a measurement (or suite of measurements) must meet to constitute convincing evidence for indigenous life (Section 2). In the Ladder (Section 3), we list characteristic features of microbial life as we know it, how specific they are to life, how they can be measured, and their propensity to meet the above criteria. In the Ladder, these features are ordered in a general sense by their likelihood (definitiveness and ease of measurement) of indicating life. In Section 4, we focus on the crux of life detection: the belief that life must be the hypothesis of last resort (Sagan et al., 1993; Anders et al., 1996; Brasier et al., 2002; Cady et al., 2003; Steele et al., 2007; Cady and Noffke, 2009; Martel et al., 2012). Building on Hand et al. (2017,
Chapter 5), we propose a method of identifying a simplistic but upgradable set of decision rules determining whether the null hypothesis ("the features are abiotic") is disproved. In light of these rules, we evaluate past attempts at life detection in Section 5 and upcoming attempts in Section 6.

\section{Criteria for a Claim of Life Detection}

Criteria for a detection of life define the burden of proof that must be met to convince a majority of the scientific community of such a discovery. These criteria depend on the community and the discovery and become established as claims are made and debated (e.g., Schopf, 1993; M.D. Brasier et al., 2015).

Given the current understanding of life, a convincing life-detection measurement or suite of measurements must be sufficiently (1) sensitive, (2) contamination-free, and (3) repeatable; one or more features must be sufficiently (4) detectable, (5) preserved (survivable), (6) reliable (measurably different from expected abiotic signals), and (7) compatible with life as we know it; and (8) the biological interpretation must be the last-resort hypothesis. All eight criteria are summarized in Table 1.

"Sufficiently" implies a quantitative threshold above which each of the eight criteria are met. The first three criteria, which pertain to the instrument, would be assessed through positive and negative controls such as standards, blanks, and replicates. The other five, which pertain to the measurement context, are less straightforward to assess. Detectability can be informed by assessing any environmental effects (such as degradation or masking) on a positive control. Preservation and reliability can be quantified by comparing abiotic and biological source and consumption rates, but these are difficult to assess in a previously unstudied system. Compatibility is arbitrary in the sense that we necessarily limit the search to signs of life as we know it, rather than trying to imagine unfamiliar features of more exotic biology. These criteria and their metrics are described below.

\subsection{Instrumental criteria}

Sufficient instrumental sensitivity, absence of contamination interfering with the measurement, and the ability to replicate the measurement are the burden of proof for reporting data in the peer-reviewed literature. Thus, these criteria were met in past reports of life detection on and beyond Earth (Levin and Straat, 1977; Sagan et al., 1993; Schopf, 1993; McKay et al., 1996; Priscu et al., 1999; Summons et al., 1999). Given the debates surrounding these past reports, these criteria are clearly necessary but not sufficient for the detection of life.

In addition, spaceflight instruments must meet a number of other constraints presented by policy (such as planetary protection), the nature of the environment in which they operate (temperature, pressure, radiation, mechanical stresses), and constraints of mass, volume, power, data, and duration. Also desirable are the flexibility to measure unexpected signals (as cameras and spectrometers can, whereas assays and stains can only detect targeted compounds), perform nondestructive analysis, and operate in unexpected conditions (e.g., in Enceladus' plume for Cassini mass spectrometers designed to probe tenuous exospheres in the Saturn system; Waite et al., 2004, 2009, 2017). These constraints are not further considered in this paper. 
Table 1. Criteria for a Claim of Life Detection to Convince a Majority of the Scientific Community

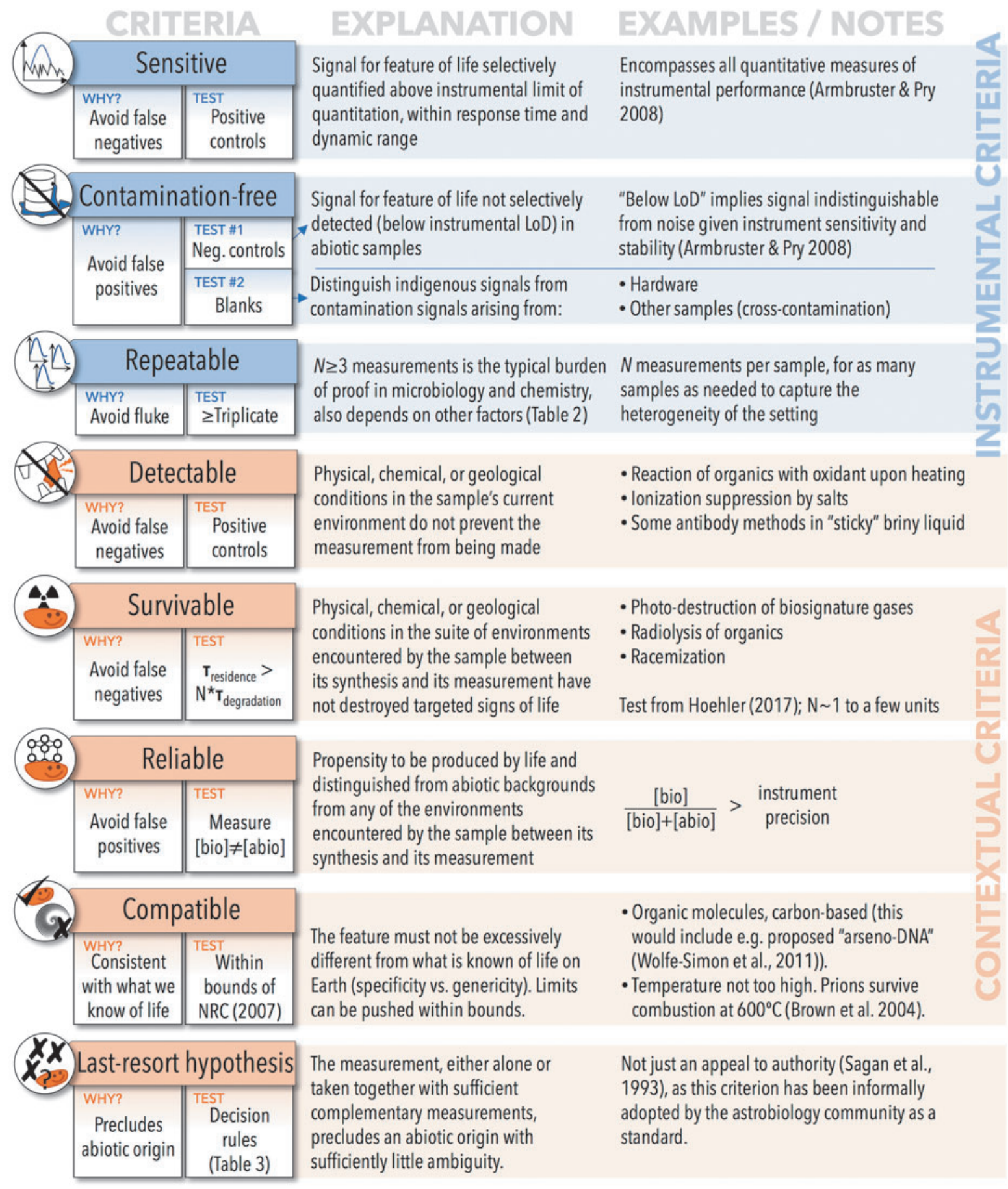

The degree to which features of life meet instrumental criteria depends on the state of the art for the techniques used to measure these features, and on how samples are acquired and processed prior to analysis. Because the state of the art is constantly improving, the degree to which these criteria are met will change. Therefore, the corresponding Ladder columns (Table 2) are a snapshot of current capabilities. In this respect, practical applicability has been emphasized at the expense of timelessness. This also implies that the corresponding entries in Table 2 are, to some extent, based on the capabilities of current instrumental techniques. We do not mean this exercise as an endorsement of particular instruments, and fully expect that techniques that remain to be flown, developed, or imagined will change the Ladder accordingly. Finally, instrumental criteria might apply to some features in the Ladder but not others (e.g., sensitivity and repeatability may not apply to searches for biofabrics). 


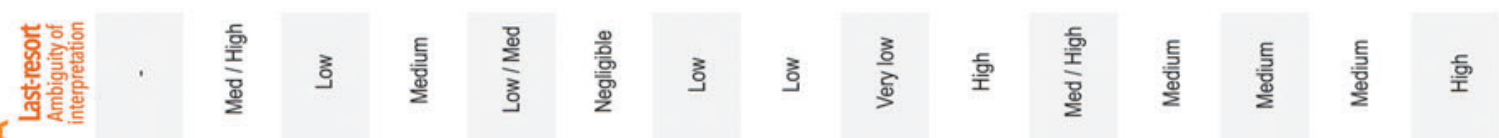

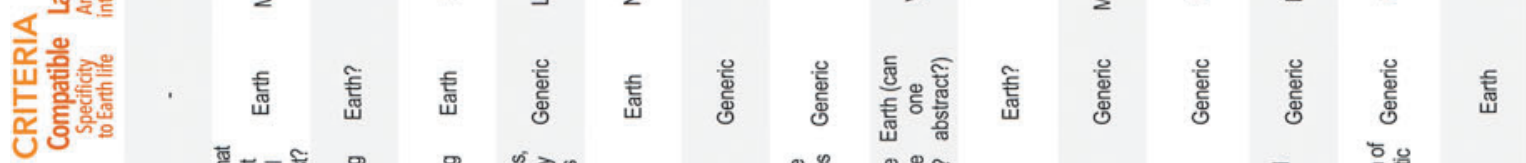

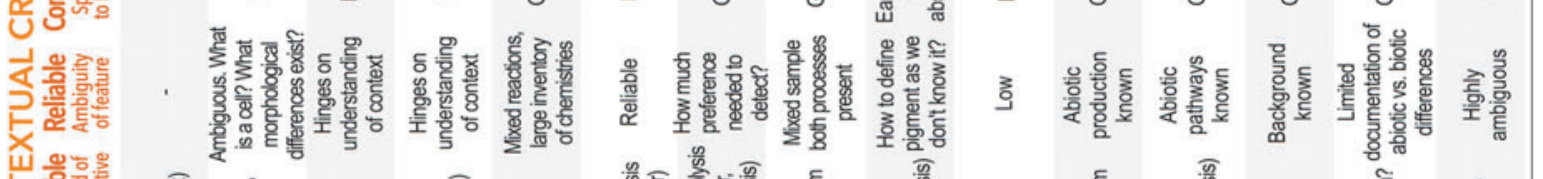

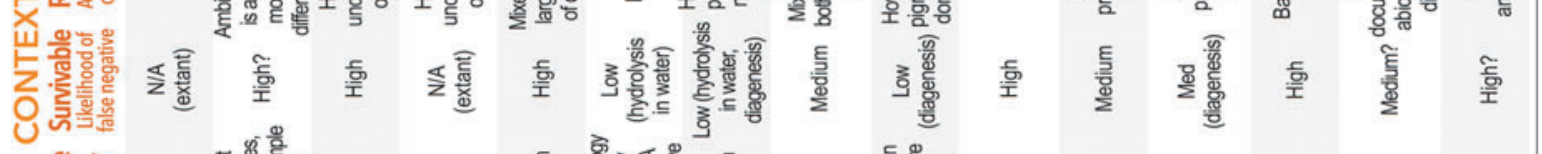

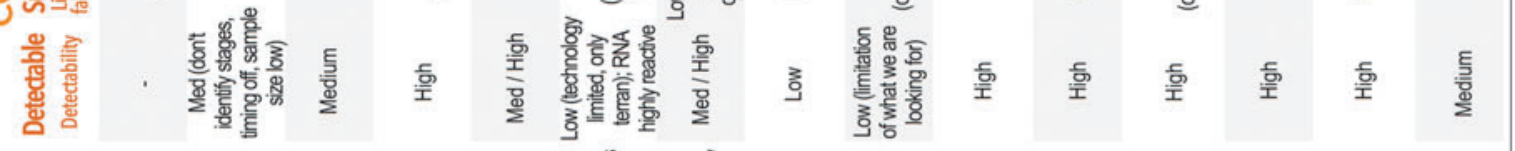

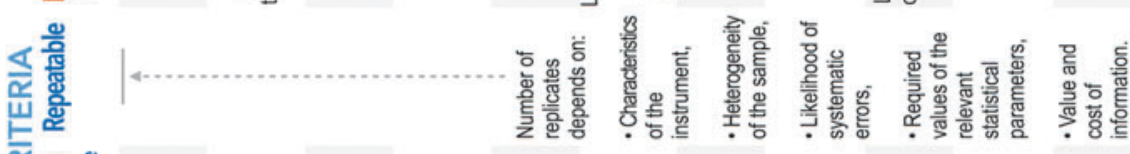

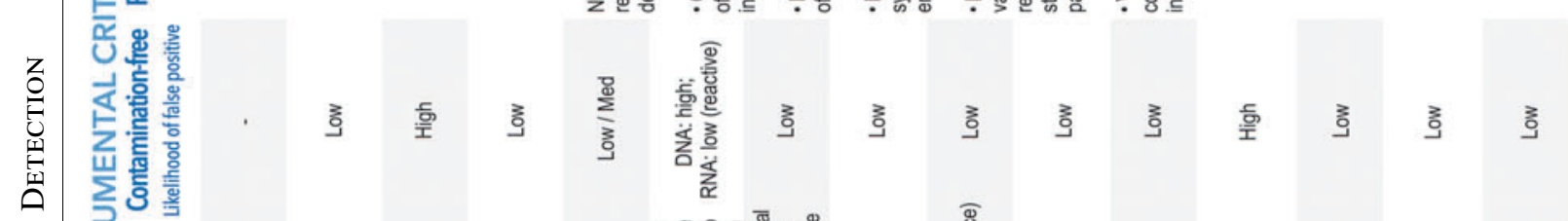

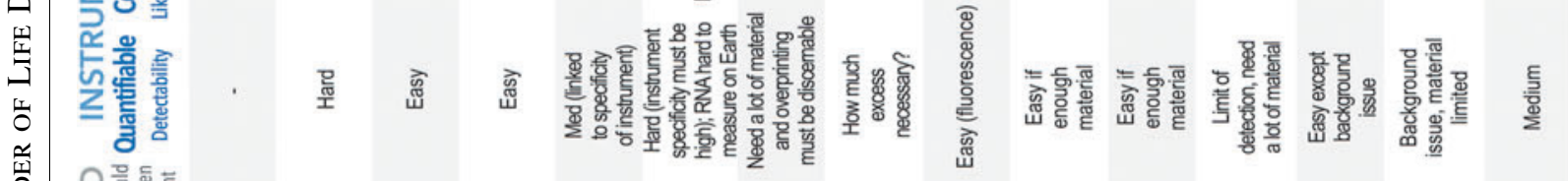

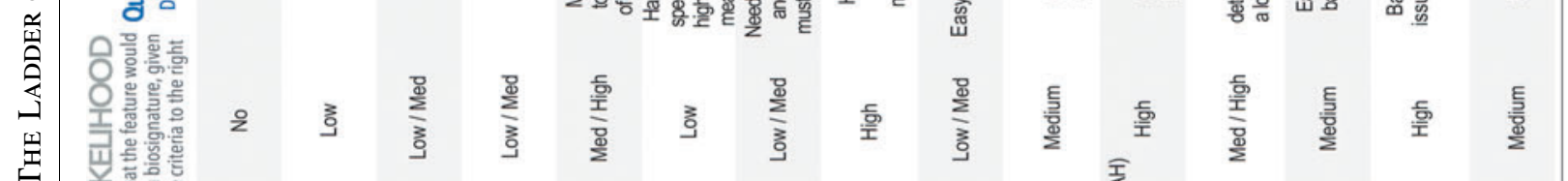

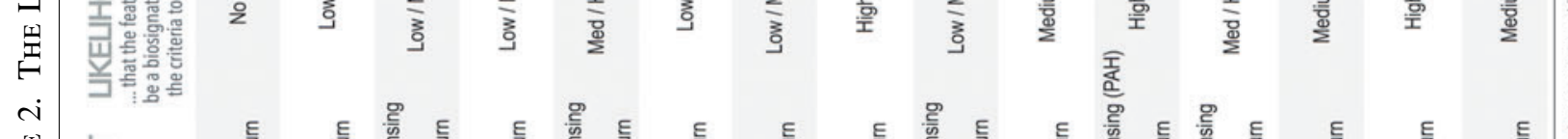

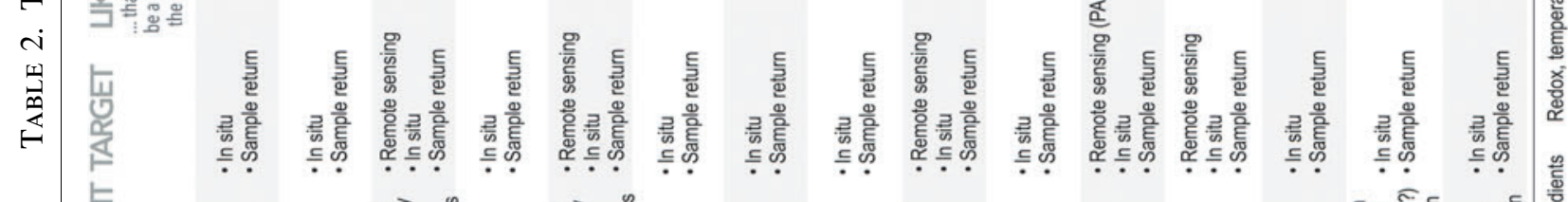

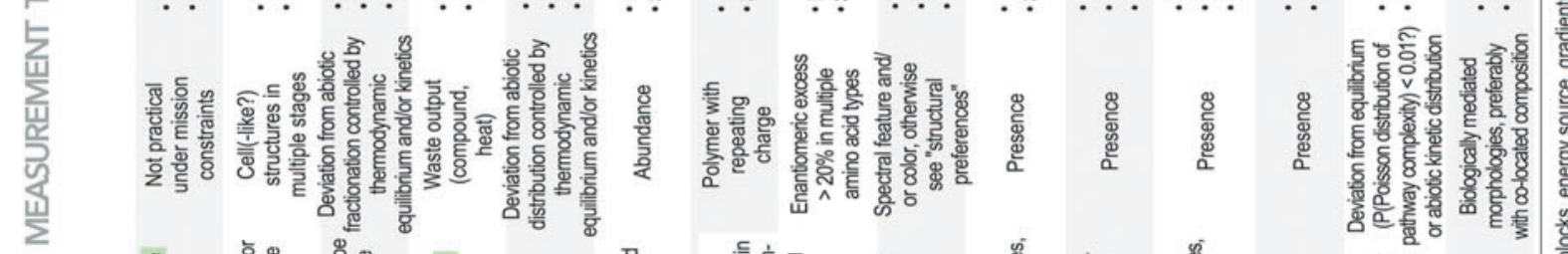

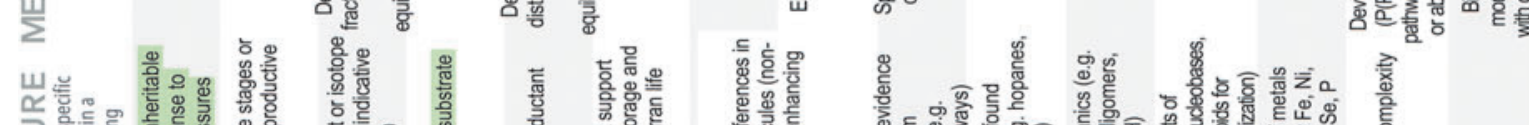

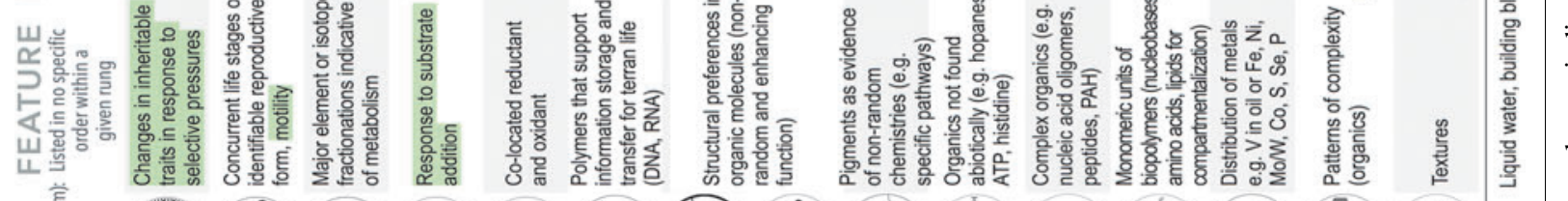

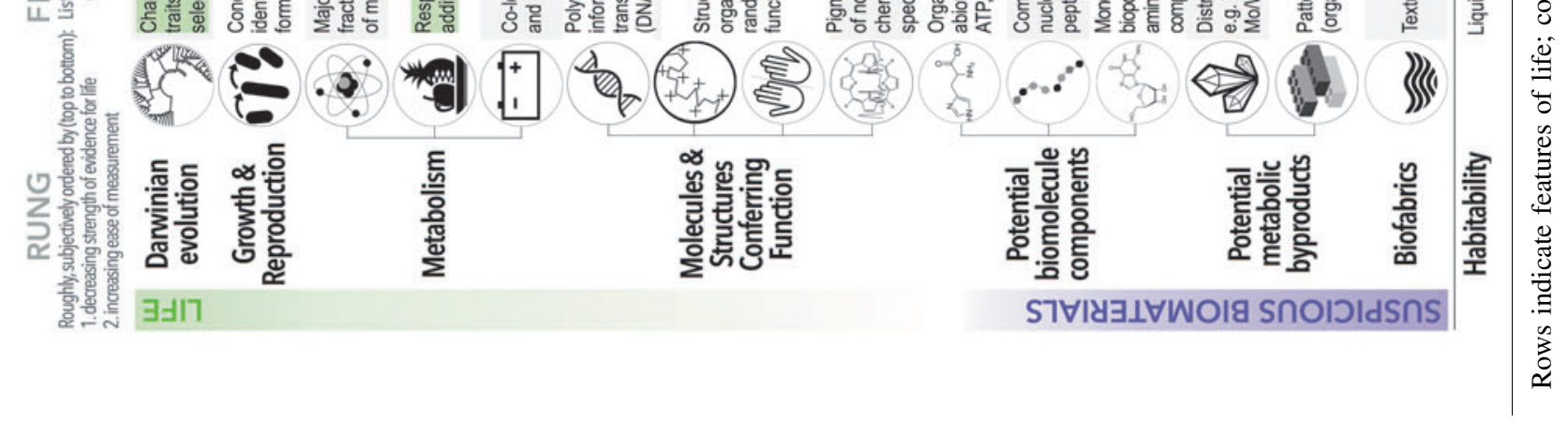


2.1.1. Sensitivity. This criterion encompasses all quantitative measures of instrumental performance. It requires that the signal for the feature of life be selectively quantified above the limit of quantitation (LoQ), within the instrumental response time and dynamic range. The LoQ is "the lowest concentration at which the analyte can not only be reliably detected but at which some predefined goals for bias and imprecision are met" (Armbruster and Pry, 2008). It is greater than or equal to the limit of detection (LoD), "the lowest analyte concentration [...] at which detection is feasible." In practice, the LoD is estimated as an arbitrary number of standard deviations above the mean of measurements on a blank. If the bias and imprecision estimates captured in the LoD meet predefined goals, then LoQ $=$ LoD; otherwise, the LoQ is the higher analyte concentration needed to meet these goals (Armbruster and Pry, 2008).

By requiring that the feature of life be quantified above the LoQ, the "sensitivity" criterion encompasses demands for sensitivity, stability, precision, and accuracy. To these qualities, we add selectivity (i.e., resolution), a response time short enough, and a dynamic range sufficiently broad to detect the analytical signal. All quantities can be determined with samples containing a known abundance of analyte (positive controls).

Instrumental capabilities depend on how data are acquired (remotely or in situ). In the case of in situ analysis, these capabilities can hinge on how the sample is acquired and prepared prior to analysis.

2.1.2. Absence of interfering contamination ("contaminationfree"). This criterion requires that any contamination signal be sufficiently well characterized that its false-positive signal can be quantifiably discriminated from the signal indigenous to the sample analyzed. It does not imply that the sample must not contain any contamination, which cannot be fully eliminated (e.g., Beauchamp and Belz, 2013).

We distinguish between contamination by signals intrinsic to the instrument hardware or method, such as crosscontamination from other samples (MEPAG Next Decade Science Analysis Group, 2008), and by spurious signals from the indigenous environments encountered by the sample. The latter are captured in the contextual criterion of reliability (Section 2.2.3). Examples of the former include solvent residues detected by the Viking gas chromatograph-mass spectrometer (GC-MS) (Biemann et al., 1977) or spectral absorption by gases in Earth's atmosphere in ground-based observations of those same gases in the atmosphere of Mars (Mumma et al., 2009). Examples of the latter include exogenic infall of abiotic meteoritic organics on planetary surfaces (Hand et al., 2017) or abiotic accumulation of atmospheric $\mathrm{O}_{2}$ as a result of photochemistry (Harman et al., 2015). Contamination intrinsic to the hardware or method also includes the overprint of processes that can confound observations, such as detector or illumination angles when observing morphologies.

Two tests can be used to screen for contamination: negative controls and blanks. In both cases, the instrumental response for the feature of life should be below the LoD for the negative control or blank. Blanks and negative controls provide assessments of the level of contamination by signals intrinsic to the instrument hardware or method as well as spurious signals from the indigenous environment.

The possibility of contamination has spurred many a debate over the indigenous character of measured biological features (Bulat et al., 2004; Lepland et al., 2005; Rasmussen et al., 2008; French et al., 2015; see Section 5). As a result, the community standards for discriminating indigenous from contamination signals are very strict. Evidence for life is accepted only if the likelihood of most of the signal being due to contamination is extremely low (e.g., Bulat et al., 2004; Christner et al., 2006). This means that evidence for indigenous life might be erroneously dismissed (false negative), but this is deemed preferable to erroneously attributing contamination signals to indigenous life (false positive). Consequently, much effort to mitigate and characterize contamination has been devoted in planning robotic space missions (Summons et al., 2014) and interpreting returned data (Elsila et al., 2009; Freissinet et al., 2015). Because each feature of life has a different propensity for contamination, we deem it essential to take this criterion into account when establishing the Ladder's structure.

2.1.3. Repeatability. The instrument must provide the same response, within uncertainty (e.g., a set number of standard deviations), to repeat measurements of a given sample under the same conditions. Three replicates (triplicates, $N=3$ ) are the community standard in biology and chemistry. However, each type of measurement has a dispersion arising from the characteristics of the instrument, heterogeneity of the sample, and the likelihood of systematic errors. The number of replicates to be measured is determined on this basis and on the required values of the relevant statistical parameters, value and cost of information. In any case, additional measurements provide further information on the uncertainty of a given result. For example, more measurements may be needed if a predefined goal for measurement precision is not met.

The repeatability criterion pertains to $N$ measurements on the same sample, rather than $N$ samples that together may constitute a heterogeneous set. $N$ measurements should be made for as many samples as needed to capture the heterogeneity of the setting. For an exoplanet's atmosphere, which covers one pixel on the detectors of current state-of-the-art telescopes (Schneider et al., 2010), one sample suffices as the signal is averaged over the entire planet, while multiple samples would be acquired in situ (Hand et al., 2017) and for return to Earth (Mustard et al., 2013).

\subsection{Contextual criteria}

Unlike instrumental aspects that can be controlled during instrument and experimental design, context can often not be established until instruments are in place, instrument checks and blanks have been run, and samples themselves are run and the first data are analyzed. This can reveal unanticipated challenges regarding the detectability, preservation, and reliability of biosignatures. Therefore, understanding context is crucial to establishing the biogenicity of any measured feature listed in Table 2. A convincing claim of life detection must also establish that the feature and its environment are compatible with what is known of life on Earth, and there 
should be no highly likely interpretation other than biology for the measurement or set of measurements (Table 1).

2.2.1. Detectability. This criterion requires that physical, chemical, or geological conditions in the sample's current environment do not prevent a detection from being made. Here, we use the word "detectability" in a meaning separate from instrumental performance, which is captured in the "sensitivity" criterion. However, in some cases the detectability of a feature remains intimately tied to the technique used for its measurement, because environmental conditions can affect the feature only at the time of measurement, depending on any changes made to the sample as it is measured. In the Viking GC-MS, the targeted organic compounds may have been lost to oxidation upon heating inherent to the analysis (Klein, 1978; Benner et al., 2000), but this may not have been so had the oxidants been removed or separated from the organics before analysis, or had a different method that mitigates the adverse effects of heating or that does not require heat been implemented. Other examples are ionization suppression by salts, preventing the operation of some separation-mass spectrometry techniques (Kidd et al., 2015), or solution properties such as high salinity (brine) preventing template binding of antibodies by clogging or altering receptor sites.

A sample known to contain the targeted feature (a positive control) should be analyzed to determine the detectability of the feature at the conditions of the life-detection measurement. Ideally, the control is carried out at the time and place of life detection, and under the same environmental conditions (e.g., by mixing or incubation with indigenous material during sample preparation). However, this is not always feasible in mission conditions, in which case the control measurement can be made with a duplicate instrument (flight spare) in an analogous field or laboratory setting.

The following two criteria, survivability and reliability, also affect the detectability of a feature in the broad sense of the term. Again, in our attempt to parse out these aspects, the "detectability" criterion here only evaluates whether conditions in the sample's current environment do not prevent a detection from being made.

2.2.2. Feature survivability and preservation. A feature may be created or destroyed both biologically and abiotically (Fig. 1a). "Survivability" or "preservation" is the criterion that biological sources must exceed abiotic sinks (or biological sinks exceed abiotic sources) for a biological feature to be noticeable (Fig. 1b). "Reliability," the criterion that signals due biological sources (sinks) must be distinguishable from abiotic sources (sinks), is discussed in the next section.

Living organisms can maintain their integrity under environmental pressures. However, metabolic products and waste, dead organisms, or their building blocks can degrade over time once no longer in kinetic steady-state or if not at thermodynamic equilibrium at environmental conditions. Degradation examples include atmospheric photochemistry of biosignature gases (Seager et al., 2012; Reinhardt et al., 2017), radiolysis or oxidation of organics on a planetary surface (McKay et al., 1998; Hand et al., 2017), and racemization of chiral molecules (Bada and McDonald, 1995; Bada et al., 1999; Monroe et al., 2017), among others.

Features may experience changes in conditions between their synthesis and their measurement if transported through multiple environments (e.g., from the seafloor of an oceanbearing icy moon, to the dilute subsurface ocean, through the overlying ice shell to the irradiated surface). Conditions
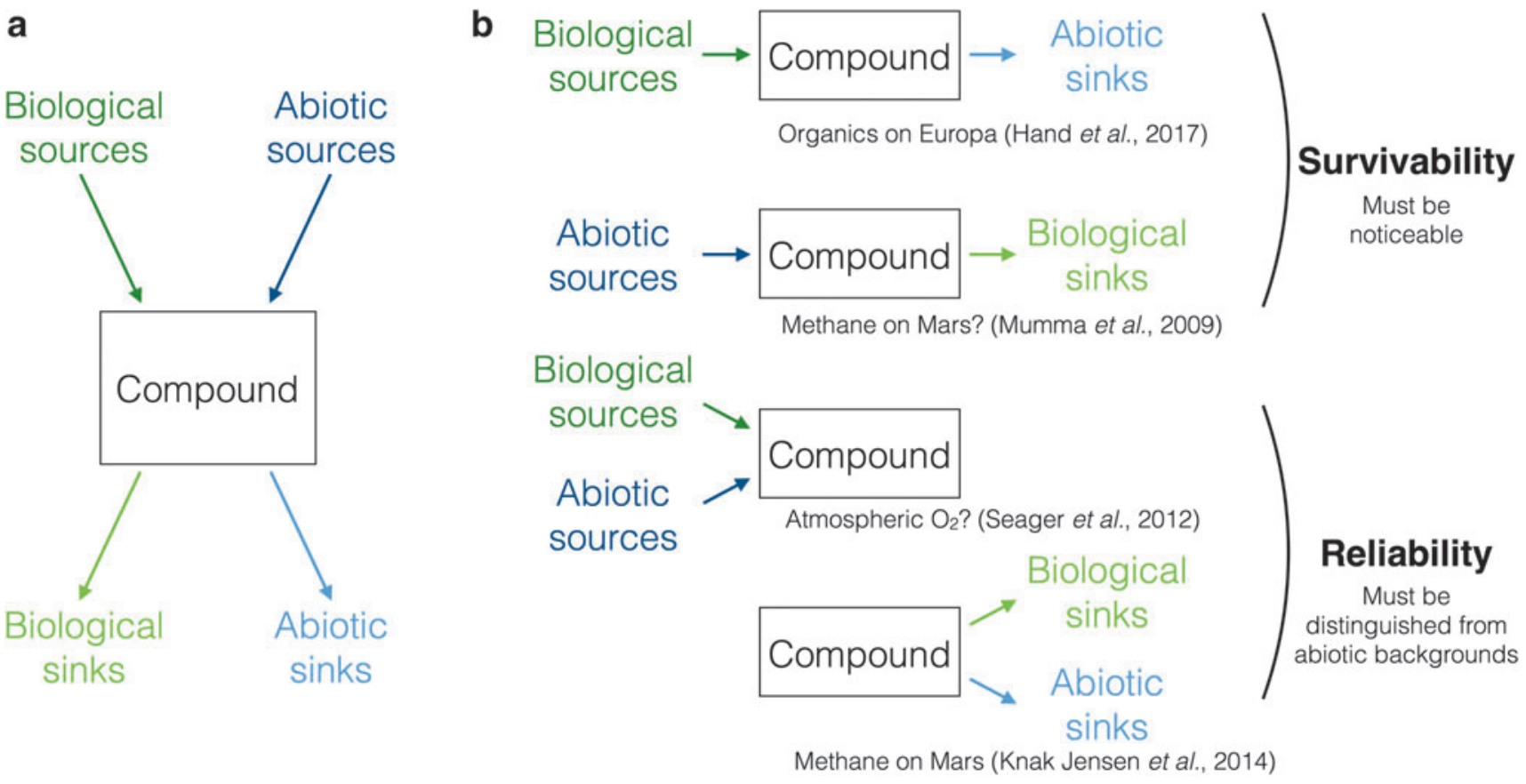

FIG. 1. (a) Any compound for which biology is a source (dark green) or sink (light green) may also have abiotic sources (dark blue) and sinks (light blue). This complicates life detection. (b) This complication is overcome by meeting the criteria of survivability (biological sources $>$ abiotic sinks or biological sinks $>$ abiotic sources) and reliability (biological sources $>$ abiotic sources or biological sinks $>$ abiotic sinks). Examples are provided for each case. 
can also change over time (e.g., atmospheric escape allowing more radiation to reach the surface, burial, exhumation due to erosion). The measured feature of life must not have become too degraded in any environment at any time. This includes conditions induced by sampling and (for sample return) other environments that can be designed to prevent further alteration of the sample: return leg mission phases, planetary protection protocols, and curation (Cady et al., 2003; Beauchamp and Belz, 2013; McCubbin et al., 2017).

These considerations also apply for the biological consumption of an abiotic compound, so that the compound's absence is the feature. An example is the reported fast disappearance of methane in the atmosphere of Mars (Mumma et al., 2009), which is difficult to explain abiotically, as it is faster than photolytic destruction (although see Knak Jensen et al., 2014). A possible counterexample is the presence of both $\mathrm{CO}_{2}$ and $\mathrm{H}_{2}$ in the plume of Enceladus despite a possible thermodynamic drive for their reaction to methane (Waite et al., 2017), which suggests that any life in Enceladus' ocean is too scant to consume all $\mathrm{H}_{2}$. In general, the absence of a compound is not a practical biosignature: it demands a contextual understanding that is often lacking, and it is not amenable to serendipitous discovery.

How much degradation is tolerable? A useful metric consists in comparing the residence time of a biological feature and its degradation timescale (Hand et al., 2017; Hoehler, 2017). The residence time is the ratio of the feature concentration to its net synthesis rate, assuming steady state between its biological sources and sinks. In the absence of steady state, one considers instead the time required for this synthesis rate to accumulate this concentration. This is equivalent to comparing the rates of biological (abiotic) synthesis and abiotic (biological) consumption. If the residence time is too short, or if degradation is faster than production such that the feature concentration is below the LoQ, the feature is destroyed for the purposes of the measurement. For morphological features, the term "concentration" can be interpreted more qualitatively, but the degradation timescale is still quantitatively set by physicochemical properties and processes such as chemical kinetics or crustal recycling (Farmer and Des Marais, 1999; Cady et al., 2003; Westall and Cavalazzi, 2011).

The strength of biological sources and sinks hinges on the size of the biomass and therefore on its supply of liquid water, energy, and nutrients. The energy supply in photic zones (surfaces) vastly exceeds that of planetary interiors where ecosystems must rely on endogenic energy. Consequently, the survivability criterion should be less easily met in searching for subsurface life (Hand et al., 2017; Hoehler, 2017).

2.2.3. Reliability or definitiveness. This criterion requires that the feature can be produced by life and distinguished from background abiotic sources or sinks for the feature measured from any of the environments encountered by the sample between its synthesis and its measurement. The sample provenance, including whether the targeted features formed together with the host mineral matrix, can be understood by integrating spatial information from molecular to planetary scales (Conrad and Nealson, 2001; Cady et al., 2003; Hand et al., 2017).
Example features with competing biological and abiotic sources include atmospheric $\mathrm{O}_{2}$ and macromolecular organic carbon in rocks. On Earth, tens of percent $\mathrm{O}_{2}$ accumulated primarily due to biological photosynthesis, but on other planets such abundances could result from the photolysis of $\mathrm{CO}_{2}$ (Seager et al., 2012). Macromolecular carbon can result from the degradation of biological matter but also from abiotic hydrothermal synthesis (Brasier et al., 2002). A dual-sink example is the disappearance of methane on Mars, which is faster than by photochemistry alone (Mumma et al., 2009). The case of methane on Mars illustrates how survivability and reliability are intertwined (Atreya et al., 2007; Fig. 1). Careful study of abiotic cycling of the features of interest is key to establishing their biogenicity (McKay et al., 1998).

The reliability of a measurement can be tested by comparing rates of biogenic and abiotic synthesis, or competing rates of degradation, and resulting feature concentrations (Hoehler, 2017) or their morphological equivalent. The ratio of biogenic to total concentration must exceed the measurement precision.

As with instrumental contamination (Section 2.1.2), the community standards for distinguishing indigenous from abiotic environmental signals are very strict. Evidence for life is accepted only if the likelihood of most of the signal being due to abiotic processes (false positive) is extremely low (e.g., Klein, 1978; Chao, 2000), even if this means that evidence for indigenous life might be erroneously dismissed (false negative). Distinguishing biological from abiotic sources for a given measurement result could be amenable to techniques of analysis such as multidimensional correlation or receiver operating characteristic curve analyses, implemented in other fields of science for similar purposes (e.g., Rienstra et al., 2000; Pepe et al., 2001). For natural systems, making this distinction will be very difficult.

2.2.4. Compatibility. This criterion requires that the feature (or set thereof) not be excessively different from what is known of life on Earth. This is sometimes of importance in assessing evidence for life in a binary way: for example, Harvey and McSween (1996) suggested that mineral evidence for a high-temperature origin of ALH84001 material precluded its ability to harbor indigenous life (Martel et al., 2012, and references therein). However, this criterion is most useful in assessing the specificity of a feature to Earth life (specificity is not a criterion in itself, as both specific and generic features have their own advantages for life detection: high specificity implies a higher likelihood of biogenicity, and high genericity implies a higher likelihood that the feature is present). For this reason, we use compatibility as a criterion to place bounds on generic features, but assess the specificity of each feature in the corresponding column of the Ladder.

Unfortunately, the features most easily attributed to biology tend to be the most Earth-life-centric (Section 3). Ideally, one would search for generic manifestations of the attributes or requirements of life (Conrad and Nealson, 2001), such as a solvent or the need for limited reactivity of its building blocks. However, an overly generic search hampers instrument design, short of knowing what specifically to look for. Target features range from highly Earth-centric (e.g., DNA or RNA) to non-aqueous solvents (e.g., formamide or hydrocarbon) and non-carbon-based biochemistry (National 
Research Council, 2007). A practical middle ground is to seek features that push the limits of life on Earth within bounds. They should be broader than just DNA, RNA, proteins, and the lipids used by Earth life, but limited to carbon-based life in water undergoing Darwinian evolution (imperfect reproduction and reproduction of imperfections, with eventual persistence of those that confer fitness). This upper bound on genericity is reasonable given the high cosmogenic supply of carbon and water (Horowitz, 1976; Owen, 1980) and the limitations of alternative building blocks and solvents (National Research Council, 2007). An example of a compatible feature would be the "arsenoDNA" suggested by Wolfe-Simon et al. (2011). It has been argued that Darwinian evolution may be enabled by compartmentalization (e.g., Szostak et al., 2001). However, other studies suggest that evolution by natural selection can occur with polymers that are not compartmentalized but instead interact freely in the environment (e.g., Fry, 2011, and references therein; Pross, 2011; Mathis et al., 2017). Therefore, even though we deem it likely that compartmentalization is an essential feature for life, we refrain from imposing it as a constraint on the compatibility criterion.

Compatibility also constrains the environments that can be searched to those that provide conditions that life on Earth can tolerate or those that preserve material from such environments. This requires establishing the provenance of any analyzed samples. Tolerable conditions, which include temperature, pressure, water activity, and radiation, are summarized in Chapter 3 of the National Research Council report (2007), bearing in mind that some biological agents tolerate broader conditions: for example, prions survive passage through $600^{\circ} \mathrm{C}$ (Brown et al., 2004). The compatibility criterion states explicitly implicit assumptions about key features of life in the Life Detection Ladder, discussed in the next section.

2.2.5. Last-resort hypothesis. The last-resort hypothesis criterion is described in Section 4.

\section{Features Diagnostic of Life: The Life Detection Ladder}

NASA's working definition of life is a "self-sustaining chemical system capable of Darwinian evolution" (Joyce, 1994; Luisi, 1998; Benner, 2010). However, a universal definition of life awaits a universal theory of life (Chao, 2000; Conrad and Nealson, 2001). In fact, getting the ability to construct such a theory from the knowledge of any other instances of life is a chief motivation for the search for life beyond Earth (Lederberg, 1960). For the time being, we are limited to searching for features of present or past life, or biosignatures (Botta et al., 2008; Domagal-Goldman, Wright, et al., 2016; Horneck et al., 2016). Biosignatures have been identified in the context of the exploration of Mars (Summons et al., 2011), Europa (Hand et al., 2017), and exoplanets (Meadows and Seager, 2010). They pertain to essential attributes of life: metabolism, growth, and reproduction, whether part of life itself or its building blocks or byproducts (Conrad and Nealson, 2001; Westall and Cavalazzi, 2011).

These features are listed in Table 2, the Ladder of Life Detection. For each, we list an associated measurement, target environment, and likelihood of detecting the feature (a one-word summary of columns to the right). Subsequent columns describe how each feature tends to satisfy each criterion of Section 2. They have two headings: one corresponding to those criteria and one that matches the original version of the Ladder published online at https://astrobiology .nasa.gov/research/life-detection/ladder. The community is welcome and encouraged to suggest improvements at this website: the Ladder is meant to evolve, not just as progress in research and instrument technology brings in enhanced or new capabilities but also as new features or complications are recognized. Example techniques are mentioned for illustrative purposes only but do not imply endorsement of a particular technique over any other and do not consider issues related to sample preparation.

Features are listed in Ladder "rungs" that distinguish to which trait of life (Darwinian evolution, growth, reproduction, metabolism, etc.) the corresponding features pertain. A bottom rung regroups all measurements needed to establish the habitability of a setting. These are a prerequisite to life detection at all levels above but are not further discussed here. Rungs and features are roughly ordered by increasing likelihood (bottom to top) that the feature is a result of some biotic process (from "suspicious biomaterials" to "life"), which is often the reverse order of the likelihood that a particular feature could be measured. However, there is room for debate regarding the specific order of each feature in the Ladder, and indeed the specific placement of the features relative to one another is highly dependent on the environment in which the measurements would be made, hence why they are grouped in broader rungs. The ordering of rungs can be debated as well. We will discuss them here from the highest levels in the current structure to the lowest.

\subsection{Darwinian evolution}

Darwinian evolution, the ability to inherit changes in genetic traits leading to the persistence of traits that confer an advantage in a given habitat, is an essential feature of life as we know it. However, Darwinian evolution takes place over many generations of organisms as conditions change. It has been deemed not practical to detect in (even relatively) unexplored natural environments in the timeframe of relevant investigations (Chyba and Phillips, 2002).

Chao (2000) offered a possible method by arguing for a modified version of the Viking Labeled Release experiment (see Section 5.1), in which soil could be added to nutrient media (rather than the reverse), serially transferred, and monitored for a response indicating growth of biomass. However, the low rate of success in culturing a given species on Earth (<1\%; Vartoukian et al., 2010; Stewart, 2012) makes a false-negative result likely. Therefore, we deem the design of a "Darwinometer" instrument able to directly detect Darwinian evolution impractical.

Alternatively, the result of Darwinian evolution may be observed in a much shorter time span, if different morphologies or compositions (phenotypes) are observed in adjacent niches, each at different environmental conditions (Benner, 2017). Such an observation, reminiscent of Darwin's finches (Darwin, 1859), would first require the observation of other features (e.g., morphologies, textures) further down the Ladder. Finally, provided that organisms could be cultured, it 
may become possible to attempt to perform directed evolution experiments (e.g., Elena and Lenski, 2003).

\subsection{Growth and reproduction}

Unlike Darwinian evolution, growth and reproduction are not unique to life, even though they are some of its central traits (Benner, 2010). They are evidenced by morphologies of concurrent life stages or an identifiable reproductive form, such as cell or cell-like structures in multiple stages (Westall et al., 2015), including motility of extant cells (Conrad and Nealson, 2001). This assumes a search for life compartmented in cells, which is the case of all life on Earth but need not be the general case (criterion \#7, Mathis et al., 2017, but see Szostak et al., 2001).

Because microbial cells are microscopic (down to $<1 \mu \mathrm{m}$; Martel et al., 2012; Hand et al., 2017, and references therein), morphological evidence for cell growth and reproduction is obtained with optical, electron, atomic force, laser scanning, and other microscopy techniques (Oehler and Cady, 2014). Many features can look like cells (reliability criterion \#6), including vesicles that can form abiotically (e.g., Georgiou and Deamer, 2014): morphology alone is not sufficient to establish biogenicity (Conrad and Nealson, 2001; Brasier et al., 2002; García Ruiz et al., 2002; Martel et al., 2012). However, cell-like features are easily recognized in images (Schopf, 1993; McKay et al., 1996), provided that morphologies are not too degraded (\#5; Farmer and Des Marais, 1999) and that environmental conditions do not dilute cells too much (\#4) as the detection limit of microscopes remains high (\#1; Bedrossian et al., 2017; Hand et al., 2017). With microscopy, contamination is easily screened out: indigenous features are those clearly embedded in the sample matrix (\#2; Cady et al., 2003).

\subsection{Metabolism}

To sustain themselves, living organisms derive energy from their environment and convert it to forms used to perform other biological functions such as maintenance, growth, reproduction, or repair. Because conversion is not fully efficient, metabolism also results in waste. Both conversion and waste intermediates or products can be evidence for ongoing biological activity, as their abundance can deviate from thermodynamic equilibrium or kinetically limited abiotic steady states. Specifically, organisms can enzymatically catalyze chemical reactions that would still occur without their presence (i.e., for which there is a thermodynamic drive from which they can derive Gibbs free energy) but that are kinetically inhibited. The fact that a reaction occurred can be evidence of biological activity, provided that it is not expected to occur at abiotic background conditions.

Such deviations include elemental or (especially) isotopic fractionations, which can be identified by mass spectrometry techniques. Specifically, metabolism tends to incorporate lighter isotopes in biomass. This is especially apparent with carbon and other light elements (Anders et al., 1996; House et al., 2000; Allen et al., 2006; Sharp, 2007). Isotopic fractionations can remain once organisms die, although the signal with light elements may be lost due to diagenesis even at low temperatures (\#5). They can be determined for specific compounds or classes thereof, provided a separation stage up- stream of the mass spectrometer. Compound-specific isotopic analyses are more limited by sample size than bulk analyses (\#1 sensitivity) but better constrain metabolic pathways. Notably, isotopic compositions that mimic those resulting from metabolism can also result from abiotic fractionation mechanisms, depending on factors such as temperature and the isotopic composition of the source pools of elements. Therefore, interpreting isotopic compositions requires knowledge of both a contextual reference level (\#6 reliability; Sharp, 2007; Webster et al., 2013) from which fractionations are quantified and either the specific pathway at play or (more likely) comparison with fractionations by Earth organisms (making this feature specific to Earth life; \#7 compatibility).

Evidence for ongoing metabolism can also be obtained by detecting waste or incorporation in response to labeled substrate addition or some other stimulation. This was the approach of the Viking biological experiments (Klein, 1978). Although these experiments targeted molecular compounds, waste heat is likely the most generic response and can be measured by techniques such as calorimetry (Maskow, 2013). However, the need for a stimulation to elicit a metabolic response makes this technique specific (\#7). In interacting with extant life, detection is likely facilitated by minimizing departure from indigenous conditions to which organisms would have adapted (Horowitz et al., 1972). If the context is well known (\#6), the measurement is easily detectable (\#4) and not susceptible to environmental degradation (\#5), since this feature results from extant life.

Finally, metabolism, which is generically based on redox reactions (\#7), can lead to colocated oxidants and reductants. $\mathrm{O}_{2}$ and $\mathrm{CH}_{4}$ metastably coexist at substantial levels in Earth's atmosphere owing to life (Owen, 1980; Sagan et al., 1993, and references therein). Evidence can also be recorded in minerals such as $\mathrm{Fe}$ or $\mathrm{Al}$ oxides not associated with silicates as terminal electron acceptors (Lower et al., 2001), especially if associated with microbial-like morphologies (Cavalazzi et al., 2012). Redox states can be assessed remotely by spectroscopy at many wavelengths, even in broad band (Grasby et al., 2003; Mikucki et al., 2009); or in situ by mineralogical characterization techniques. These survey techniques are amenable to serendipitous discovery, but to interpret measurements one must understand the background abiotic chemistry (\#6 reliability; Seager and Bains, 2015). The metastability of disequilibrium species (\#5 survivability) tends to be lower for gases and solutes than solids. The notion of "colocation" implies a spatial scale at which materials are reactive; this scale depends on the reactions at play.

\subsection{Functional molecules and structures}

Functional molecules are more prone to contamination than the above features (\#2) but more likely to be measured because they are more generic (\#7), more likely preserved $(\# 5)$, or more sensitively measured (\#1).

Functional features include polymers that support information storage, information transfer, and functions such as catalysis; specific structural preferences in organic molecules; and pigments. The functional polymers of terran life are DNA, RNA, and proteins. They are detectable at very low levels (\#1) with microbiological analysis techniques, and more generic chemical methods of hydrolysis followed by identification of nucleobases (e.g., Kaur and Halliwell, 
1996). Unlike other biomaterials, DNA, RNA, and proteins (at least those made of the 20 or so amino acids used by terran life) are very specific to life on Earth (\#7 compatibility), but this makes it extremely unlikely, at least for DNA and proteins, that they would be synthesized abiotically (\#6), particularly in longer chain lengths. RNA is easily hydrolyzed in (especially alkaline) water (\#5), so the likelihood of contamination is low (\#2). It is higher for DNA and proteins, which are not as easily hydrolyzed (e.g., Radzicka and Wolfenden, 1996); DNA otherwise degrades mainly by depurination (Bada et al., 1994). In addition, high-energy sampling (e.g., in a high-velocity plume flyby) may fragment polymers too much to establish a biological origin (Benner, 2017).

Life's complex organic building blocks comprise structural preferences that are not random and enhance their function. Polymers with a repeating backbone charge such as DNA and RNA facilitate Darwinian evolution by being able to undergo mutations (e.g., in nucleobases) that do not cause major changes in their chemical properties, dominated in liquid water by the repeating charge (Benner, 2017). There is currently no method to detect a repeating backbone charge, but a polycharged detector may be implemented (Benner, 2017). A repeated charge is difficult to mimic abiotically (\#6) and more generic than DNA or RNA (\#7). However, as with DNA and RNA, its survivability in liquid water is limited by hydrolysis (\#5; National Research Council, 2007), and its detectability may be hampered by dilution (\#4).

Another structural preference is homochirality, which enhances multiple functions such as catalytic capability for proteins via folding or nucleic acid resilience in chemical properties to random mutations. Just like a repeating charge, chirality sets the geometry (conformation) of a polymer, helping preserve its structure even if another part of the molecule is affected. Most of life on Earth uses D-sugars and L-amino acids (Bada et al., 1998; Blackmond, 2011), although there are rare exceptions (Newton, 1970; Lam et al., 2009; Martinez-Rodriguez et al., 2010; Moazeni et al., 2010; Zhou et al., 2012; Zhang and Sun, 2014); these do not prevent the use of chirality as a possible biosignature. Abiotic enantiomeric excesses up to $20 \%$ have been measured in meteorite samples (Cronin and Pizzarello, 1997; Glavin and Dworkin, 2009). These can be plausibly amplified in evaporitic settings owing to unequal solubilities between homochiral and racemic crystals (Breslow and Levine, 2006; Klussmann et al., 2006; Breslow and Cheng, 2009), but all large values measured in natural samples are biological (\#6; Hand et al., 2017, and references therein). Large enantiomeric excesses can be sensitively detected (\#1) with separation techniques coupled with mass spectrometry (Goesmann et al., 2017; Hand et al., 2017). Their survivability (\#5) depends on the amino acid and strongly on temperature (Monroe et al., 2017).

Benner (2017) argued that combined evidence for a repeating charge and homochirality would rule out a system in which no encoding of information takes place, but at the expense of a loss in generality. This reasoning aligns with "decision rules" to determine whether the suite of measurements precludes an abiotic origin (\#8; Section 4).

Pigments are used by terran life for specific biochemical pathways such as photosynthesis and therefore evidence nonrandom chemistries. Aside from some organic compounds, isotopic fractionations, and colocated oxidants and reductants, pigments are the only feature detectable remotely (Sagan et al., 1993; Seager et al., 2005; Kiang et al., 2007). Pigments such as chlorophyll, which has a prominent and specific red edge spectral feature (\#1) used in remote sensing of vegetation on Earth, are unambiguously biogenic (\#G). However, they are specific to Earth life (\#7) and may have taken time to evolve (\#4; Reinbothe et al., 1996). Although predicting what structures pigments might take is difficult, the detection techniques are not targeted and therefore are susceptible to serendipitous discovery.

\subsection{Potential biomolecule components}

Biomolecule components comprise organic compounds not found abiotically (e.g., hopanes derived from hopanoid membrane compounds, adenosine triphosphate [ATP], or the amino acid histidine), as well as other organics such as polycyclic aromatic hydrocarbons (PAHs), lipids, nucleobases, or amino acids, present either individually or as small oligomers such as peptides or nucleic acids (Westall et al., 2015; Goesmann et al., 2017). Compounds in the second category are less reliably attributed to biology than the above functional molecules (e.g., Becker et al., 1997) but are more likely to be detected.

The above compounds can be sensitively detected (\#1) by techniques such as separation-mass spectrometry, which can operate in diverse environments (\#4 detectability). They are more easily preserved than biopolymers (\#5; Gu et al., 1999; Aksyonov and Williams, 2001; Burchell et al., 2014) and more generic (\#7). However, the detection of those compounds that can be formed abiotically (\#6 reliability; Meierhenrich et al., 2004; Martins et al., 2008; Cleaves et al., 2009; Martel et al., 2012) does not establish biogenicity (\#8) without an in-depth knowledge of abiotic processes that can cycle them.

Among basic monomeric units, especially relevant are nucleobases, amino acids, and lipids (fatty acids, esters, carboxylic acids), the respective building blocks of nucleic acids that store genetic information, proteins that carry out biological functions, and membranes that compartmentalize organisms (Georgiou and Deamer, 2014). These features meet the eight criteria in the same way as more complex organics but are easier to detect, more generic, and more easily produced abiotically.

\subsection{Potential metabolic byproducts}

Potential metabolic byproducts are distributions of species that differ from those resulting solely from abiotic thermodynamic equilibrium or kinetic steady state. They include distributions of elements present at trace levels in biological matter, but which can carry essential metabolic functions at the active sites of enzymes (Novoselov et al., 2017), and patterns of complexity in mixtures of organics (Marshall et al., 2017).

Distributions of elements (e.g., $\mathrm{V}, \mathrm{Fe}, \mathrm{Ni}, \mathrm{Mo} / \mathrm{W}, \mathrm{Co}, \mathrm{S}$, Se, P) can be measured in situ (e.g., Meslin et al., 2013; VanBommel et al., 2016) or remotely, but with more difficulty (\#1; Prettyman et al., 2017). Generally, the in situ techniques can sensitively measure elemental abundances (\#1) unimpeded by environmental factors (\#4). Elemental 
abundances may be the most survivable Ladder feature (\#5). They are fairly generic (\#7; Conrad and Nealson, 2001; Neveu et al., 2016; Novoselov et al., 2017; Stern et al., 2017), as biological uses of an element hinge on its properties (e.g., valence), even though several elements can be used to perform the same function (e.g., V, Fe, and/or Mo for nitrogen fixation; Hoffman et al., 2014). However, abiotic backgrounds must be understood at relevant spatial scales to properly interpret any deviations (\#6; Cady et al., 2003; Storrie-Lombardi and Nealson, 2003). On its own, this feature would not convince a majority of the community of the presence of life (\#8; Section 4).

Patterns of complexity in organics may be more convincing because organics make up most of dry biomass. Cyclic metabolic pathways can result in the repeated addition of a compound, leading to characteristic patterns in the distribution of biogenic organics (Lovelock, 1965; McKay, 2004; McDonald and Storrie-Lombardi, 2006; Eigenbrode, 2008; Summons et al., 2008). They require life to have evolved to this level of complexity, which could preclude its detection at the most primitive stages (Benner, 2017). Another approach relies on measuring the complexity of an organic mixture, such as the distribution of the number of types of operations needed to obtain each molecule in the mixture ("pathway complexity"; Marshall et al., 2017). Either approach can distinguish biological from abiotic distributions, the latter often being Poisson distributions. Mixtures can be characterized by mass spectrometry and subsequent statistical analysis.

Patterns in organic distributions carry weight in deciding whether a suite of measurements precludes an abiotic origin $(\# 8)$ : this feature has been incorporated as an essential aspect of life-detection missions (Anderson et al., 1972; MEPAG Next Decade Science Analysis Group, 2008; McKay et al., 2014; Reh et al., 2016; Hand et al., 2017). It is generic (\#7) and rather easy to detect (\#1), although possibly precluded by environmental factors such as the oxidants on the surface of Mars (\#4). Even simple organics are relatively sensitive to degradation (\#5; MEPAG Next Decade Science Analysis Group, 2008). Moreover, there is only limited documentation

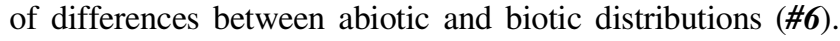
Contamination can be assessed ( $\# 2)$ by complementary (e.g., isotopic) analyses (Elsila et al., 2009).

\subsection{Biofabrics}

Terran microbial communities can affect the morphology of their environment, creating lamination (stromatolites), mounds, or microbially induced sedimentary structures (Westall et al., 2011; Noffke, 2015). These biofabrics are easier to detect than smaller cell-like morphologies (\#1) but more prone to abiotic mimicking (\#6). Indeed, cell-like features are used to establish the biogenicity of larger-scale fabrics (A.T. Brasier et al., 2015, and references therein). Thus, like cell-like morphologies, biofabrics alone cannot preclude abiotic interpretations (\#8; Cady et al., 2003). Biofabrics meet criteria \#2, 3-5, and 7 (propensity for contamination, detectability, preservation, and compatibility) in much the same way as cell-like features.

The interpretation of both biofabrics and cell-like features is considerably strengthened by elemental, isotopic, or mineralogical mapping of the morphologies (McKay et al., 1996; Cady et al., 2003; Rasmussen et al., 2008; Cavalazzi et al., 2011; Oehler and Cady, 2014). In addition, a database of macro- and microscale images of morphologies resembling biology would inform assessments of their biogenicity in future efforts (Cady et al., 2003).

\section{Decision Rules for Rejecting Abiotic Hypotheses}

The interpretation of successful measurements is the crux of life detection. Let us assume that measurements satisfy the first seven criteria (sensitivity, absence of interfering contamination, repeatability, detectability, survivability, reliability, and compatibility) despite any instrumental or environmental challenges. This has been achieved several times (Section 5). Yet the majority opinion for many attempts is that they did not compellingly preclude an abiotic origin. This has driven the community to adopt a standard of skepticism such that successful measurements will be interpreted as signs of life only if there is no satisfactory interpretation involving solely abiotic processes: in the words of Sagan et al. (1993), "life is the hypothesis of last resort." Moreover, these past attempts have led the community to establish as a standard that a set of measured features is needed to form a basis for interpretation (Conrad and Nealson, 2001; MEPAG Next Decade Science Analysis Group, 2008; Westall and Cavalazzi, 2011; Mustard et al., 2013; Reh et al., 2016; Hand et al., 2017; Vago et al., 2017; see Table 5).

Hand et al. (2017) provided a possible interpretation framework. They considered combinations of measurements, assigning a binary result to each ( 1 if successful, 0 otherwise) and to the overall outcome ( 1 if an abiotic origin is precluded, 0 otherwise). For example, they postulated that, provided contextual knowledge that rules out an exogenic origin for organics (criterion \#6), the measurements of (a) abundances of complex organics and (b) a large enantiomeric excess in some of these organics would be sufficient to rule out abiotic hypotheses (overall outcome of 1), even in the absence of detectable patterns in organic mixtures, isotopic fractionations, morphologies, or mineralogical evidence for life $\left(7^{\text {th }}\right.$ case in their Table 5.1).

One may rightfully object that a binary approach to life detection is a great oversimplification of the outcome of combinations of measurements and contextual information on both the environment and the life-detection approach. This outcome may be more carefully assessed probabilistically (Chao, 2000): for each measurement, one may consider the null hypothesis that the measurement does not indicate indigenous biological sources and estimate the probability (e.g., the $p$-value) that this hypothesis is correct. If this probability is below a given threshold, then the community may consider that there is sufficient basis to claim life detection. Unfortunately, the complexity of this probabilistic framework is such that we do not know what probability values to assign to realistic situations. For the time being, and to stimulate further discussion, we opt to discuss below binary rules as proxies for probabilistic estimates: results of 1 represent estimates of probabilities that fall below the rejection threshold of the null hypothesis, and vice versa. Bearing in mind the limitations of such binary frameworks, we speculate below on possible decision rules as an example of how the Ladder might be used to inform interpretations of life-detection measurements.

The nine measurements considered by Hand et al. (2017) led to $2^{9}=512$ combinations. The 15 features listed in Table 2 


\begin{tabular}{|c|c|c|c|c|}
\hline \multirow{2}{*}{\multicolumn{2}{|c|}{ Feature }} & \multicolumn{3}{|c|}{ Permutations } \\
\hline & & $\mathbf{A}$ & B & C \\
\hline 60 & Morphologies & 0 & 0 & 1 \\
\hline & Isotopic fractionations & 0 & 1 & 1 \\
\hline & Mineralogical evidence & 0 & 0 & 0 \\
\hline & Large enantiomeric excess & 1 & 1 & 1 \\
\hline & Complex organics & 1 & 1 & 1 \\
\hline & Patterns in organic mixtures & 0 & 0 & 0 \\
\hline & ife Detection Result & 1 & 1 & 1 \\
\hline
\end{tabular}

FIG. 2. In a binary framework, if we attribute a lifedetection result of 1 to case A ("the presence of complex organics and large enantiomeric excesses together in a sample cannot be achieved abiotically"), then cases B and C, with additional evidence for life, would also have a result of 1 . Therefore, there would be no need to consider each case individually: case A would be a "decision rule" determining the outcome of cases B, C, and all others with complex organics and a large enantiomeric excess. In a probabilistic framework, the result of each measurement matters.

lead to $2^{15}$ or $\sim 33,000$ cases. In a binary framework, each needs not be considered individually. In the example above, a combination with the same measurements but isotopic fractionations consistent with life would also yield an overall outcome of 1 , as would cases in which patterns, morphologies, or mineralogical evidence for life is detected (Fig. 2). They could be grouped under a single decision rule stating that "complex organics and a large enantiomeric excess are good enough" regardless of other measurements, which at best would reinforce the conclusion. In a probabilistic framework, however, such additional measurements would be essential, as the combined probability that the set of measurements validates or disproves the abiotic null hypothesis would depend on the result of each measurement.

One could also decide that a negative result (probability of abiotic null hypothesis above a set threshold) for a measurement defaults the overall result to 0 ; that is, an abiotic origin cannot be precluded. For example, the nondetection of indigenous organics by the Viking GC-MS was sufficient to reach the consensus that an abiotic origin could not be precluded to interpret the results of Viking's three substrateaddition experiments, irrespective of their consistency with biology (Klein, 1978). (Adding to the ambiguity of the Viking results was the lack of a postulated abiotic null hypothesis to disprove.)

Thus, the number of decision rules should be greater than 1 but smaller than $2^{N}$, with $N$ the number of features (measurements). A useful set of rules must balance simplicity and comprehensiveness. A minimalistic example of 11 rules (A through $\mathrm{K}$ ) is proposed in Tables 3 and 4.

The first three rules (A, B, and C) state that finding evidence for Darwinian evolution, a spectral signature of pigments, or DNA/RNA, respectively, would preclude an abiotic origin even in the absence of any other feature; these are the "smoking guns" of Table 4. We emphasize that such rules are debatable: for example, it might be that smallmolecular-mass organic or mineral pigments are the product of abiotic, catalyzed chemistry. Again, such uncertainty as to their origin would be better captured with probabilistic rather than binary results. The results of combinations in which Darwinian evolution, DNA, RNA, and pigments are not detected are decided by the remaining rules.

Rules D and E consider cases of evidence for cell-like features. Such evidence, in the absence of evidence for other features, would be insufficient to conclude that the cell-like features cannot be abiotic, given debates on old

Table 3. Description of Decision Rules for Rejecting Abiotic Hypotheses (Criterion \#8)

Rule Description

A Evidence for Darwinian evolution precludes an abiotic origin even in the absence of any other feature.

B Evidence for a spectral signature of pigments precludes an abiotic origin even in the absence of any other feature.

C Evidence for DNA or RNA precludes an abiotic origin even in the absence of any other feature.

D Evidence for both cell-like features and structural preferences in organics (nonrandom and enhancing function, such as a repeating charge or chirality) precludes an abiotic origin.

E Evidence for both cell-like features and patterns of complexity in organics precludes an abiotic origin.

F Evidence for both a response to stimulation and structural preferences in organics precludes an abiotic origin.

G Evidence for both a response to stimulation and patterns of complexity in organics precludes an abiotic origin.

$\mathrm{H} \quad$ Evidence for both structural preferences and patterns of complexity in organics precludes an abiotic origin.

I Without evidence for structural preferences in organics, and unless one of the above rules applies, an abiotic origin cannot be precluded.

$\mathrm{J}$ Without evidence for patterns of complexity in organics, and unless one of the above rules applies, an abiotic origin cannot be precluded.

$\mathrm{K}$ Without evidence for either structural preferences or patterns of complexity in organics, an abiotic origin cannot be precluded, regardless of whether there is evidence for cell-like morphologies or a response to stimulation. 
Table 4. Example Set of Decision Rules for Rejecting Abiotic Hypotheses (Criterion \#8)

\begin{tabular}{|c|c|c|c|c|c|c|c|c|c|c|c|c|c|}
\hline \multirow{3}{*}{$\begin{array}{l}\text { Ladder } \\
\text { Rung }\end{array}$} & \multirow[b]{3}{*}{ Feature } & \multirow[b]{3}{*}{ Measurement } & \multicolumn{11}{|c|}{ Decision rules (account for all possible combinations $=2^{\# \text { features }}$ ) } \\
\hline & & & A & B & C & D & E & $\mathbf{F}$ & G & \begin{tabular}{|c|}
$\mathrm{H}$ \\
\end{tabular} & I & $\mathrm{J}$ & $\mathrm{K}$ \\
\hline & & & \multicolumn{3}{|c|}{$\begin{array}{l}\text { Smoking } \\
\text { guns }\end{array}$} & \multicolumn{2}{|c|}{\begin{tabular}{|} 
Strong morphological \\
evidence, but \\
biochemical \\
evidence lifts the \\
ambiguity of abiotic \\
(mineral) \\
morphologies \\
\end{tabular}} & \multicolumn{2}{|c|}{$\begin{array}{l}\text { Strong metabolic } \\
\text { evidence, but } \\
\text { biochemical } \\
\text { evidence needed } \\
\text { for confirmation } \\
\text { (Viking 1976) }\end{array}$} & $\begin{array}{c}\text { Life is uniquely } \\
\text { cyclical rather } \\
\text { than linear. } \\
\text { Small number } \\
\text { of common } \\
\text { intermediates. }\end{array}$ & \multicolumn{2}{|c|}{\begin{tabular}{|c} 
yrebiotic Titan \\
with \\
unequilibrated \\
minerals could \\
have 1s in all \\
blank cells
\end{tabular}} & $\begin{array}{c}\text { Abiotic } \\
\text { meteoritic } \\
\text { matter } \\
\text { could } \\
\text { have 1s in } \\
\text { all blank } \\
\text { cells } \\
\end{array}$ \\
\hline $\begin{array}{l}\text { Darwinian } \\
\text { Evolution }\end{array}$ & $\begin{array}{c}\text { Changes in inheritable } \\
\text { traits in response to } \\
\text { selective pressures }\end{array}$ & Not possible & 1 & 0 & 0 & 0 & 0 & 0 & 0 & 0 & 0 & 0 & 0 \\
\hline $\begin{array}{c}\text { Growth \& } \\
\text { Repro- } \\
\text { duction }\end{array}$ & $\begin{array}{l}\text { Concurrent life stages } \\
\text { or identifiable } \\
\text { reproductive form }\end{array}$ & $\begin{array}{c}\text { Cell(-like?) structures } \\
\text { in multiple stages }\end{array}$ & & & & 1 & 1 & 0 & 0 & 0 & 0 & 0 & \\
\hline \multirow{3}{*}{ Metabolism } & $\begin{array}{c}\text { Major element or } \\
\text { isotope fractionations } \\
\text { indicative of } \\
\text { metabolism }\end{array}$ & $\begin{array}{c}\text { Deviation from abiotic } \\
\text { fractionation controlled } \\
\text { by thermodynamic } \\
\text { equilibrium and/or } \\
\text { kinetics }\end{array}$ & & & & & & & & & & & \\
\hline & $\begin{array}{c}\text { Response to substrate } \\
\text { addition }\end{array}$ & \begin{tabular}{|c|} 
Waste output \\
(compound, heat) \\
\end{tabular} & & & & & & 1 & 1 & 0 & 0 & 0 & \\
\hline & $\begin{array}{l}\text { Co-located reductant } \\
\text { and oxidant }\end{array}$ & $\begin{array}{c}\text { Deviation from abiotic } \\
\text { equilibrium and/or } \\
\text { kinetics }\end{array}$ & & & & & & & & & & & \\
\hline \multirow{3}{*}{$\begin{array}{l}\text { Functional } \\
\text { molecules }\end{array}$} & $\begin{array}{l}\text { Polymers that support } \\
\text { information storage } \\
\text { and transfer for terran } \\
\text { life (DNA, RNA) }\end{array}$ & Abundance & & & 1 & 0 & 0 & 0 & 0 & 0 & 0 & 0 & 0 \\
\hline & $\begin{array}{l}\text { Structural preferences } \\
\text { in organic molecules } \\
\text { (non-random and } \\
\text { enhancing function) }\end{array}$ & \begin{tabular}{|c|}
$\begin{array}{c}\text { Polymer with } \\
\text { repeating charge }\end{array}$ \\
$\begin{array}{c}\text { Enantiomeric excess }> \\
20 \% \text { in multiple amino } \\
\text { acid types }\end{array}$ \\
\end{tabular} & & & & 1 & 0 & 1 & 0 & 1 & 1 & 0 & 0 \\
\hline & $\begin{array}{c}\text { Pigments as evidence } \\
\text { of non-random } \\
\text { chemistries }\end{array}$ & $\begin{array}{l}\text { Spectral feature } \\
\text { and/or color }\end{array}$ & & 1 & 0 & 0 & 0 & 0 & 0 & 0 & 0 & 0 & 0 \\
\hline \multirow{3}{*}{$\begin{array}{c}\text { Potential } \\
\text { biomolecule } \\
\text { components }\end{array}$} & $\begin{array}{c}\text { Organics not found } \\
\text { abiotically (e.g., } \\
\text { hopanes, ATP, } \\
\text { histidine) } \\
\end{array}$ & Presence & & & & & & & & & & & \\
\hline & $\begin{array}{c}\text { Complex organics } \\
\text { (nucleic acid } \\
\text { oligomers, peptides, } \\
\text { PAH) }\end{array}$ & Presence & & & & & & & & & & & \\
\hline & $\begin{array}{l}\text { Monomeric units of } \\
\text { biopolymers } \\
\text { (nucleobases, amino } \\
\text { acids, lipids for } \\
\text { compartmentalization) }\end{array}$ & Presence & & & & & & & & & & & \\
\hline \multirow[b]{2}{*}{$\begin{array}{c}\text { Potential } \\
\text { metabolic } \\
\text { byproducts }\end{array}$} & Distribution of metals & \begin{tabular}{|c|} 
Presence \\
\end{tabular} & & & & & & & & & & & \\
\hline & $\begin{array}{l}\text { Patterns of complexity } \\
\text { (organics) }\end{array}$ & $\begin{array}{c}\text { Deviation from abiotic } \\
\text { equilibrium and/or } \\
\text { kinetics }\end{array}$ & & & & & 1 & & 1 & 1 & 0 & 1 & 0 \\
\hline Biofabrics & Textures & $\begin{array}{c}\text { Biologically mediated } \\
\text { morphologies, } \\
\text { preferably with co- } \\
\text { located composition } \\
\end{array}$ & & & & & & & & & & & \\
\hline \multicolumn{3}{|c|}{ Life Detection Result } & 1 & 1 & 1 & 1 & 1 & 1 & 1 & 1 & 0 & 0 & 0 \\
\hline
\end{tabular}

The table is read by columns. 
microfossils (Schopf, 1993; Brasier et al., 2002) and celllike features in the ALH84001 martian meteorite (McKay et al., 1996; Martel et al., 2012). However, these rules assert that complementary evidence for either structural preferences in organics (nonrandom and enhancing function, such as a repeating charge or chirality) or patterns of complexity in organics, together with the morphological evidence, would preclude an abiotic origin.

Rules $\mathrm{F}$ and $\mathrm{G}$ consider cases in which a Viking-type substrate-addition experiment provides results compatible with life. In the absence of evidence for any other feature, this would not preclude abiotic interpretations (Klein, 1978). However, together with the response to substrate addition, evidence for either structural preferences (Rule F) or patterns of complexity in organics (Rule G) would convincingly preclude an abiotic origin.

Rules H, I, and J consider cases without evidence for morphology or response to stimulation. They assert that evidence for both structural preferences and patterns of complexity would convincingly exclude all abiotic interpretations (Rule $\mathrm{H}$ ), but if evidence for either is lacking, then an abiotic interpretation could not be precluded (Rules I and J, respectively). Indeed, a lifeless Titan could have organics with large enantiomeric excesses and organic polymers with a repeating charge, if prebiotic synthesis goes slightly further than in analog experiments (Cable et al., 2012; Rule I). Similarly, evidence for patterns of complexity without evidence for structural preferences enhancing function would be insufficient evidence for life (Rule J). In both cases, any evidence for isotopic fractionations or distributions of inorganic species unexpected from abiotic thermodynamics or kinetics could reflect an incomplete understanding of the sample provenance, even if criterion \#6 were deemed satisfied based on current knowledge.

Rule $\mathrm{K}$ asserts that regardless of results on morphologies and substrate addition, a lack of evidence for both structural preferences and patterns of complexity in organics would be enough to dismiss the interpretation that only life could have caused those results. Indeed, measurements of abiotic meteoritic matter could yield results consistent with life if evidence was collected for each of the other features: morphologies (as in ALH84001, Section 5), isotopic fractionations (caused by, e.g., water-rock reaction kinetics; Cole and Chakraborty, 2001; Pizzarello and Shock, 2010), response to substrate addition (by oxidation as in the Viking results), colocated oxidant and reductant (as in ALH84001), complex organics (Meierhenrich et al., 2004; Martins et al., 2008; Pizzarello and Shock, 2010; Martel et al., 2012), amino acids without a strong enantiomeric excess (Pizzarello, 2016), lipids (Nagy, 1966), and an atypical distribution of metals (Friedrich et al., 2002).

We have not sought consensus on how reasonable these rules are. One could object that Rule $\mathrm{K}$ is undermined if a response to substrate addition is measured, and it has been established that there are no abiotic oxidants in the sample able to generate it. Such objections can be addressed by moving to a quantitative probabilistic framework, in which the probability estimate that the measurement indicates abiotic processes is lower if the absence of oxidants able to cause a similar response has been established.

These decision rules can be concatenated into the Ladder (Table 2), expanding the last column on the ambiguity of interpretation. In this simplistic framework, some Ladder features would play no role. These include isotopes, colocated oxidant and reductant, simple organics, elemental distributions, and biofabrics (Table 4). However, they would be essential in estimating the probability of whether the set of measurements indicates life. We emphasize again that binary decision rules are not adequate to accurately assess life-detection outcomes, as these must be quantified via the probability that the null hypothesis (measurements cannot be ascribed to indigenous biology) is correct. Progress is under way to quantify such probabilities for some Ladder features, such as deviation from thermodynamic equilibrium in isotopic, gas, mineral, or organic abundances (Conrad and Nealson, 2001; Seager and Bains, 2015) and structural complexity in organics (Marshall et al., 2017). However, for other features, the quantification of measurement results with respect to an abiotic null hypothesis is still lacking. When is a given isotopic fractionation still considered abiotic (0), and when is it considered biotic (1)? When is a response to substrate addition considered abiotic (0) and biotic (1, the Viking conundrum)? When are distributions of metals, or sedimentary textures, indicative of abiotic processes (0) or biotic ones (1)? For such measurements, further community discussion would help define rejection thresholds for the abiotic null hypothesis. Finally, the relative importance of features may also depend on where and how measurements are carried out, such that the sets of rules most relevant to, for example, the exoplanet and ocean world communities may be different.

\section{Application to Past Attempts at Life Detection}

\subsection{Viking}

The Viking landers were the only life-detection missions ever flown. They carried three substrate-addition experiments: the Gas Exchange (GEx), Labeled Release (LR), and Pyrolitic Release (PR), as well as a GC-MS seeking organics (Klein et al., 1976; Klein, 1978). The GEx experiment used a gas chromatograph to identify and quantify any gases released by martian soil samples first humidified then wetted by a nutrient solution (Oyama, 1972; Oyama et al., 1976). The LR consisted in injecting ${ }^{14} \mathrm{C}$-labeled nutrients into soil samples and monitoring any release of radioactive gas $\left(\mathrm{CO}_{2}\right.$ or possibly $\mathrm{CH}_{4}$; Levin and Straat, 1977, 2016). The PR sought evidence of microbial incorporation of radiolabeled ${ }^{14} \mathrm{CO}_{2}$ and/or ${ }^{14} \mathrm{CO}$ into organic matter by measuring radioactive gas evolved from heated incubated soil, with gases evolved from organics isolated via a trapping column (Horowitz et al., 1972, 1977). All experiments were carefully designed so as to meet criteria \#1-3 and 7 and test for \#4-6:

\#1-Sensitivity: Tests on Earth ascertained the GEx sensitivity (Oyama et al., 1976). The LR rapidly detected life down to 30 cells per sample in diverse extreme environments and microbial cultures, including Earth soil placed at martian surface conditions for several days prior to analysis (Levin and Straat, 2016, and references therein). The PR was successfully tested on terran soils (Horowitz et al., 1977, and references therein). Gas chromatography-mass spectrometry analyses of Antarctic soil showed a detection limit of part-permillion down to part-per-billion levels (Biemann et al., 1977).

\#2-Absence of contamination: The microbial and chemical cleanliness of hardware was ascertained before launch (Klein et al., 1976; Meltzer, 2011). The PR chambers had 
lamps whose UV radiation was cut out to avoid photochemical organic synthesis or damage to any indigenous life. Blank gas chromatography-mass spectrometry analyses reproducibly detected only a few sub-part-per-million contaminants.

\#3-Repeatability: On Mars, four replicate GEx experiments were performed on each of five separate soil samples. LR responses were obtained four times, twice at each lander location. The PR performed seven successful incubations on aliquots from six soil samples, excluding controls. The GCMS comprised three ovens. Since one oven in each lander was inoperable, a total of four samples were analyzed.

\#4-Detectability: In the GEx, no changes in the gas composition were noted prior to nutrient addition. Upon humidification, $\mathrm{CO}_{2}, \mathrm{~N}_{2}$, and surprisingly (both in rapidityhours - and abundance) $\mathrm{O}_{2}$ were released (Oyama and Berdahl, 1977). The LR response on Mars was in the range of soil responses on Earth, but unlike in the GEx, soils stored for months in the dark produced no response. For all PR aliquots except two, carbon compounds trapped in the column were detected. The amounts of organics inferred from the GEx and PR experiments were below the GC-MS LoD (Biemann et al., 1977; Horowitz et al., 1977). Indeed, the GC-MS only detected $\sim 15 \mathrm{ppb}$ of $\mathrm{CH}_{3} \mathrm{Cl}$ in one sample and $\mathrm{CH}_{2} \mathrm{Cl}_{2}$ in another; any other species were also seen in the blank. Both, along with similar compounds, were later detected by the GC-MS onboard the Mars Science Laboratory (MSL) (Glavin et al., 2013; Freissinet et al., 2015). Although initially attributed to solvent contamination (Biemann et al., 1977), some of these compounds now seem at least partly indigenous (Freissinet et al., 2015). Detectable organics are likely present elsewhere on Mars (e.g., below the surface), as they are found in martian meteorites (McKay et al., 1996; Steele et al., 2013) in which they seem partly indigenous (Anders et al., 1996; Becker et al., 1997; Jull et al., 2000; Steele et al., 2007, 2012).

\#5-Survivability was met by default by the substrateaddition experiments, which targeted active metabolism. Organic destruction rates by oxidation and UV irradiation must yield steady-state concentrations below parts per million, competing with meteoritic infall that otherwise would have accumulated about $\leq 1000$ ppm abiotic organics (Biemann et al., 1977; McKay et al., 1998; ten Kate, 2010).

\#6-Reliability: The GEx, LR, and PR distinguished biogenic from abiotic responses by heating samples to 145 $175^{\circ} \mathrm{C}$ for $3 \mathrm{~h}$ in at least one control. Some LR and PR incubations were also carried out at $\sim 50^{\circ} \mathrm{C}$ and $90^{\circ} \mathrm{C}$, respectively. In addition, in the GEx, incubations of the same sample were repeated with fresh nutrient: a biological reaction would persist, whereas an abiotic one would decrease or cease (Oyama and Berdahl, 1977). On Mars, as on Earth, the LR did not detect a response in heat-sterilized samples, and responses at $50^{\circ} \mathrm{C}$ were several-fold weaker than at $10^{\circ} \mathrm{C}$ (Levin and Straat, 1977). However, the response was not suppressed in either the GEx (at $145^{\circ} \mathrm{C}$ ) or PR controls (at $90^{\circ} \mathrm{C}$, but $90 \%$ decrease at $175^{\circ} \mathrm{C}$ ). $\mathrm{O}_{2}$ release in the abiotic GEx control suggested an abiotic oxidizer stable at $145^{\circ} \mathrm{C}$ in the soil. The slower $\mathrm{CO}_{2}$ emission was attributed to nutrient oxidation by another soil oxidizer reacting more slowly. The LR response was attributed to a third oxidant, able to partially oxidize the labeled organics, but destroyed partially at $50^{\circ} \mathrm{C}$ and fully by storage over months (Klein, 1978).

These oxidants remain unidentified (Zent and McKay, 1994; McKay et al., 1998, and references therein; Quinn et al., 2013; Levin and Straat, 2016). Among candidate species (Klein, 1978; Tsapin et al., 2002; Kounaves et al., 2014), perchlorates $\left(\mathrm{ClO}_{4}{ }^{-}\right)$were detected by Phoenix (Hecht et al., 2009; Navarro-González and McKay, 2011, and references therein) and MSL (Glavin et al., 2013). The LR oxidant could not be perchlorate, stable at $160^{\circ} \mathrm{C}$, but could be its irradiation products (Quinn et al., 2013). None of these oxidants can explain PR responses strong at $10^{\circ} \mathrm{C}$ and $90^{\circ} \mathrm{C}$ but weak at $175^{\circ} \mathrm{C}$, nor was any other plausible process identified (Klein, 1978). Oxychlorides could react with organics to form the compounds detected by the GC-MS and $\mathrm{CO}_{2}$. The path of oxidation to $\mathrm{CO}_{2}$ involves carboxylic acid intermediates, which form faster than they are oxidized and could accumulate as metastable carboxylate salts stable at $400-500^{\circ} \mathrm{C}$, as hot as the Viking GC-MS could heat up (Benner et al., 2000).

\#7-Compatibility with life on Earth: experiments were performed in chambers at about $10^{\circ} \mathrm{C}$ and $\sim 0.1$ bar, illuminated or in the dark. The nutrients added to martian soil comprised $\mathrm{CO}_{2}$ and $\mathrm{CO}$ and aqueous solutions of racemic amino acids, chloride, sulfate, ammonium, nitrate, and other organic and inorganic salts, amines and carboxylic acids, and nucleobases that could be metabolized by diverse species on Earth (e.g., Ljungdahl and Wood, 1969).

\#8-Last-resort hypothesis: Although the Viking instruments targeted most Ladder features, the scarcity of detectable organics precluded the investigation of many (Table 5). Potential pigments or biofabrics were not seen at the spatial and spectral resolution of the cameras (Klein, 1978) or by subsequent missions (although see Noffke, 2015). Taken together, the Viking results did not convince a majority that they precluded an abiotic origin (Klein, 1978; McKay et al., 1996; Dick, 2006; ten Kate, 2010; Goetz et al., 2016; but see Levin, 2015). The example decision framework of Section 4 would lead to the same conclusion (Rule K).

Levin and Straat (2016, and references therein) interpreted the LR results alone as biological: freshly collected psychrophiles in the martian soil would quickly consume the supplied nutrients to release $\mathrm{CO}_{2}$, be partially inactivated at $50^{\circ} \mathrm{C}$, and be killed both by storage at $>10^{\circ} \mathrm{C}$ for months and heating at $160^{\circ} \mathrm{C}$ for $3 \mathrm{~h}$. To lift the ambiguity, they proposed follow-on LR experiments with each enantiomer of chiral nutrients. With the decision framework of Section 4 , a response to only one enantiomer would preclude an abiotic interpretation (Rule F), but responses to both enantiomers would allow it (Rule K).

\subsection{Oldest microfossils}

This example illustrates life detection initially based mainly on one line of evidence: morphologies. The prolonged debate on the biogenicity of these features has driven investigations of complementary Ladder features, advancing the standard of life detection.

Schopf (1993) reported the detection of microorganisms indigenous to 3.5 billion-year-old rocks in Western Australia, based on optical microscopy of cell-like morphologies. These observations are challenged by the metamorphism that these rocks had undergone (\#5) and possible subsequent contamination by Earth's ubiquitous biosphere (\#2). The samples were found to be sedimentary, suggesting provenance from a habitable setting (\#7). Cell-like features of various sizes, some in pairs (suggesting growth and reproduction) were seen 
Table 5. Application of the Decision Rules of Tables 3 and 4 to Past Measurements that Led to the Claim of Life Detection

\begin{tabular}{|c|c|c|c|c|c|c|c|c|c|}
\hline \multirow{2}{*}{$\begin{array}{l}\text { Ladder } \\
\text { Rung }\end{array}$} & \multirow{2}{*}{ Feature } & \multirow{2}{*}{ Measurement } & \multirow{2}{*}{$\frac{\text { Viking a }}{\text { In situ }}$} & \multirow{2}{*}{\begin{tabular}{|c|}
$\begin{array}{c}\text { Oldest } \\
\text { microfossils } \mathrm{b}\end{array}$ \\
$\begin{array}{c}\text { "Sample } \\
\text { return" }\end{array}$ \\
\end{tabular}} & \multirow{2}{*}{$\begin{array}{c}\begin{array}{c}\text { Earth from } \\
\text { Galileo }{ }^{c}\end{array} \\
\text { Remote } \\
\text { sensing }\end{array}$} & \multirow{2}{*}{$\begin{array}{c}\text { ALH } \\
84001 \text { d } \\
\text { "Sample } \\
\text { return" }\end{array}$} & \multirow{2}{*}{$\begin{array}{l}\text { Archean } \\
\text { lipids } h, i, j \\
\text { "Sample } \\
\text { return" } \\
\end{array}$} & \multirow{2}{*}{\begin{tabular}{|c|}
$\begin{array}{c}\text { Lake Vostok } \\
\text { accretion ice k }\end{array}$ \\
$\begin{array}{c}\text { "Sample } \\
\text { return" }\end{array}$ \\
\end{tabular}} & \multirow{2}{*}{\begin{tabular}{|c|} 
Mars \\
methane $\mathrm{p}$ \\
Remote \\
sensing \\
\end{tabular}} \\
\hline & & & & & & & & & \\
\hline $\begin{array}{l}\text { Darwinian } \\
\text { Evolution }\end{array}$ & $\begin{array}{c}\text { Changes in inheritable } \\
\text { traits in response to } \\
\text { selective pressures }\end{array}$ & Not possible & & & $N / A$ & & & & $\mathrm{~N} / \mathrm{A}$ \\
\hline $\begin{array}{l}\text { Growth \& } \\
\text { Repro- } \\
\text { duction }\end{array}$ & $\begin{array}{c}\text { Concurrent life stages } \\
\text { or identifiable } \\
\text { reproductive form }\end{array}$ & $\begin{array}{c}\text { Cell(-like?) } \\
\text { structures in } \\
\text { multiple stages }\end{array}$ & & OM, AFM & $\mathrm{N} / \mathrm{A}$ & $\begin{array}{l}\text { Carbonate } \\
\text { globules? }\end{array}$ & & $\begin{array}{l}\text { Staining/ } \\
\text { OM, SEM k }\end{array}$ & $\mathrm{N} / \mathrm{A}$ \\
\hline \multirow{3}{*}{ Metabolism } & $\begin{array}{c}\text { Major element or } \\
\text { isotope fractionations } \\
\text { indicative of } \\
\text { metabolism }\end{array}$ & $\begin{array}{c}\text { Deviation from } \\
\text { abiotic fractionation } \\
\text { controlled by } \\
\text { thermodynamic } \\
\text { equilibrium and/or } \\
\text { kinetics }\end{array}$ & & C isotopes & & C isotopes? & $\begin{array}{l}\text { C isotopes } \\
\text { (IRMS, GC- } \\
\text { IRMS) }\end{array}$ & $\begin{array}{c}\mathrm{NO}_{3}-/ \mathrm{Cl} \text { ratio } \\
(\mathrm{IC})^{k}\end{array}$ & \\
\hline & $\begin{array}{c}\text { Response to substrate } \\
\text { addition }\end{array}$ & $\begin{array}{c}\text { Waste output } \\
\text { (compound, heat) }\end{array}$ & GEx, PR, LR & & $N / A$ & & & $\begin{array}{l}\text { Cultures ', } \\
\text { Labeled } \\
\text { substrate } \\
\text { addition } \mathrm{m}, \mathrm{n} \\
\end{array}$ & $\mathrm{N} / \mathrm{A}$ \\
\hline & $\begin{array}{c}\text { Co-located reductant } \\
\text { and oxidant }\end{array}$ & \begin{tabular}{|c|} 
Deviation from \\
abiotic equilibrium \\
and/or kinetics \\
\end{tabular} & & & $\mathrm{O}_{2}, \mathrm{CH}_{4}$ & $\begin{array}{c}\text { OM, } \\
\text { SEM/TEM- } \\
\text { EDS } d, \text { AFM } \mathrm{e} \\
\end{array}$ & $\begin{array}{c}\text { Ox and red } \\
\text { C }\end{array}$ & $\begin{array}{l}\text { Ox and red } \\
\mathrm{Fe}^{\mathrm{m}} \text { and } \mathrm{N}^{\mathrm{n}}\end{array}$ & Near-IR \\
\hline \multirow{4}{*}{$\begin{array}{l}\text { Functional } \\
\text { molecules }\end{array}$} & \begin{tabular}{|c|} 
Polymers that support \\
information storage \\
and transfer for terran \\
life (DNA, RNA) \\
\end{tabular} & Abundance & GC-MS & & $\mathrm{N} / \mathrm{A}$ & & & 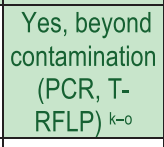 & $\mathrm{N} / \mathrm{A}$ \\
\hline & \multirow{2}{*}{$\begin{array}{l}\text { Structural preferences } \\
\text { in organic molecules } \\
\text { (non-random and } \\
\text { enhancing function) }\end{array}$} & $\begin{array}{c}\text { Polymer with } \\
\text { repeating charge }\end{array}$ & & & N/A & & & & N/A \\
\hline & & \begin{tabular}{|c|} 
Enantiomeric \\
excess $>20 \%$ in \\
multiple amino acid \\
types \\
\end{tabular} & & & $\mathrm{N} / \mathrm{A}$ & $\mid \begin{array}{l}\text { Yes, but from } \\
\text { Earth (HPLC) }\end{array}$ & & & $\mathrm{N} / \mathrm{A}$ \\
\hline & $\begin{array}{c}\text { Pigments as evidence } \\
\text { of non-random } \\
\text { chemistries }\end{array}$ & $\begin{array}{l}\text { Spectral feature } \\
\text { and/or color }\end{array}$ & & & $\begin{array}{l}\text { Vegetation } \\
\text { red edge }\end{array}$ & & & & \\
\hline \multirow{3}{*}{\begin{tabular}{|c|} 
Potential \\
biomolecule \\
components
\end{tabular}} & $\begin{array}{c}\text { Organics not found } \\
\text { abiotically (e.g., } \\
\text { hopanes, ATP, } \\
\text { histidine) } \\
\end{array}$ & Presence & GC-MS & $\begin{array}{l}\text { Kerogen } \\
\text { (Raman) }\end{array}$ & $\mathrm{N} / \mathrm{A}$ & PAH $\left(\mu \mathrm{L}^{2}-\mathrm{MS}\right)$ & $\begin{array}{l}\text { Kerogen } \\
\left(\text { GC-MS) }{ }^{i}\right.\end{array}$ & & $\mathrm{N} / \mathrm{A}$ \\
\hline & $\begin{array}{c}\text { Complex organics } \\
\text { (nucleic acid } \\
\text { oligomers, peptides, } \\
\text { PAH) }\end{array}$ & Presence & GC-MS & & $\mathrm{N} / \mathrm{A}$ & & & HPLC m & $\mathrm{N} / \mathrm{A}$ \\
\hline & $\begin{array}{c}\text { Monomeric units of } \\
\text { biopolymers } \\
\text { (nucleobases, amino } \\
\text { acids, lipids for } \\
\text { compartmentalization) }\end{array}$ & Presence & GC-MS & & $\mathrm{N} / \mathrm{A}$ & $\begin{array}{c}\text { Earth amino } \\
\text { acids (HPLC) } \mathrm{f}\end{array}$ & & & N/A \\
\hline & Distribution of metals & Presence & & & $\mathrm{N} / \mathrm{A}$ & & & & $\mathrm{N} / \mathrm{A}$ \\
\hline & $\begin{array}{c}\text { Patterns of complexity } \\
\text { (organics) }\end{array}$ & $\begin{array}{c}\text { Deviation from } \\
\text { abiotic equilibrium } \\
\text { and/or kinetics }\end{array}$ & GC-MS & & $N / A$ & & $\begin{array}{c}\text { No even/odd } \\
\text { or branching } \\
\text { preferences } \\
\text { in alkanes } \\
\end{array}$ & & N/A \\
\hline Biofabrics & Textures & $\begin{array}{l}\text { Biologically } \\
\text { mediated } \\
\text { morphologies }\end{array}$ & & $\mathrm{OM}$ & $\mathrm{N} / \mathrm{A}$ & $\begin{array}{l}\text { Carbonate } \\
\text { globules? }\end{array}$ & & & $\mathrm{N} / \mathrm{A}$ \\
\hline \multicolumn{3}{|c|}{ Life Detection Result } & 0 & 0 & 1 & 09 & 0 & 1 & 0 \\
\hline
\end{tabular}

${ }^{\mathrm{a}}$ Klein (1978). ${ }^{\mathrm{b}}$ Schopf (1993). ${ }^{\mathrm{c} S a g a n}$ et al. (1993). ${ }^{\mathrm{d}}$ McKay et al. (1996). ${ }^{\mathrm{e}}$ Steele et al. (1998). ${ }^{\mathrm{f}}$ Bada et al. (1998). ${ }^{\mathrm{g}}$ Martel et al. (2012). ${ }^{\mathrm{h}}$ Summons et al. (1999). ${ }^{\mathrm{i}}$ French et al. (2015). ${ }^{\mathrm{j}}$ Brocks et al. (2003a, 2003b). ${ }^{\mathrm{k}}$ Priscu et al. (1999). ${ }^{\mathrm{l} C h r i s t n e r}$ et al. (2001). ${ }^{\mathrm{m}} \mathrm{Christner}$ et al. (2006). ${ }^{\mathrm{n}} \mathrm{Karl}$ et al. (1999). ${ }^{\circ}$ Bulat et al. (2004). ${ }^{\mathrm{p}}$ Formisano et al. (2004), Krasnopolsky et al. (2004), Mumma et al. (2009).

$\mathrm{AFM}=$ atomic force microscopy. GC-IRMS = gas chromatography-isotope ratio mass spectrometry. IC=ion chromatography. IRMS = isotope ratio mass spectrometry. $\mathrm{OM}=$ optical microscopy. 
in replicate samples capturing the heterogeneity of the rock formation (\#3).

Carbon isotopic fractionations were consistent with metabolism such as photosynthesis, and the cell-like features were deemed composed of degraded organics, based at the time on color (Schopf and Kudryavtsev, 2012). Organic compositions were later confirmed by Raman spectroscopy (Schopf et al., 2002; M.D. Brasier et al., 2002, 2015) with any contamination from immersion oil or pencil markings excluded (\#2). Finally, major biological elements (CHNOPS) were detected in the organic matter (De Gregorio et al., 2009; Schopf and Kudryavtsev, 2012, and references therein).

The biogenic interpretation was disputed (Brasier et al., 2002). Increasing the field of view and depth of field revealed increased branching, filament diameter, and interspersed mineral grains appearing as septa or division. Such morphologies could be formed abiotically as mineral grain rims (\#6). The provenance was reattributed to a hydrothermal vein based on stratigraphic, textural, and elemental scanning electron microscopy-energy dispersive spectroscopy (SEMEDS) analyses at kilometer to micrometer scales (M.D. Brasier et al., 2015). Oxygen isotopes and the inferred presence of native metal suggested formation above $250^{\circ} \mathrm{C}$, most likely too hot for life (\#7; but see, e.g., Schrenk et al., 2003). Hydrothermalism can drive abiotic organic synthesis with carbon isotopic abundances compatible with measurements (\#6). The association of cell-like morphologies with primary minerals was also disputed, and organic distributions mapped by transmission electron microscopy (TEM) seem uncorrelated with cell-like features at the submicrometer scale (M.D. Brasier et al., 2015, and references therein). The isotopic and Raman measurements alone were deemed insufficient to establish biogenicity.

Indeed, in the example decision framework of Section 4, morphologies and elemental, isotopic, and organic compositions consistent with biology are insufficient to preclude an abiotic origin (Rule K) without information on the structures or patterns of organics (Rules D-E). Information on functional groups was obtained (De Gregorio et al., 2009; Schopf and Kudryavtsev, 2012, and references therein), but not in enough detail to determine whether structures enhance function or whether there are any patterns, as the samples were too degraded (\#5).

\subsection{Earth from Galileo}

On its way to Jupiter, the Galileo spacecraft flew by and observed Earth, informing life detection by remote sensing. Its near-IR spectrometer detected abundant atmospheric $\mathrm{O}_{2}$ via its absorption at $0.76 \mu \mathrm{m}, \mathrm{CH}_{4}$ at $3.3 \mu \mathrm{m}, \mathrm{CO}_{2}, \mathrm{H}_{2} \mathrm{O}$, and tentatively $\mathrm{O}_{3}$ and $\mathrm{N}_{2} \mathrm{O}$ (Sagan et al., 1993). Colocated oxidants $\left(\mathrm{O}_{2}\right.$ and $\left.\mathrm{CO}_{2}\right)$ and reductants $\left(\mathrm{CH}_{4}\right)$ in thermodynamic disequilibrium were inconsistent with known abiotic sources and sinks such as photochemistry (\#6). In an $\mathrm{O}_{2}$-rich

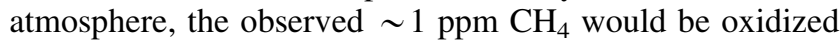
to $\mathrm{CO}_{2}$ and $\mathrm{H}_{2} \mathrm{O}$ within 10 years, needing fast replenishment to accumulate at the observed levels (\#5; Sagan et al., 1993). $\mathrm{Had} \mathrm{O}_{2}$, a diatomic molecule, not been detected owing to its lack of significant vibrational absorption (\#4), its presence could have been inferred from its photochemical product $\mathrm{O}_{3}$, detected more definitively by Galileo's UV spectrometer (Sagan et al., 1993).
Abiotic carbon cycling by water-rock interactions was inferred: Earth's bulk density is consistent with a rocky composition, and surface solid and liquid $\mathrm{H}_{2} \mathrm{O}$ were detected by measuring thermal emission at $5 \mu \mathrm{m}$ (temperature) and reflectance spectroscopy, including areas of low (liquid water) and high (ice, glint) albedo. These are conditions compatible with life (\#7).

Galileo broadband images also showed a sharp contrast in reflectance near $700 \mu \mathrm{m}$ (Sagan et al., 1993). Such a contrast is incompatible with common silicate or metal materials, prompting consideration of a globally distributed biological pigment (here, chlorophyll). This alone is sufficient evidence for rejecting abiotic interpretations, according to our example decision framework (Rule B). However, the biological interpretation was strengthened by the detection of atmospheric disequilibrium. Galileo's remote sensing instruments could not measure isotopic fractionations in Earth's atmosphere. A similar remote-sensing investigation of the Earth was performed with the OSIRIS-REx spacecraft (Lauretta et al., 2018), leading to the same conclusions.

\subsection{ALH84001}

This example illustrates a very careful assessment of contamination in the investigation of several Ladder features. It also helped advance the standard of life detection: the combined evidence was deemed insufficient to preclude an abiotic interpretation, largely owing to a lack of organic features.

McKay et al. (1996) reported evidence for several features consistent with life in the martian meteorite ALH84001. This rock crystallized 4.5 billion years ago and contains ancient carbonate globules (seen with SEM/TEM-EDS) and $\geq 1 \mathrm{ppm}$ PAHs (detected by microprobe two-step laser mass spectrometry $\left.\left[\mu \mathrm{L}^{2}-\mathrm{MS}\right]\right)$, both formed along fractures. Then, the surface of Mars likely provided conditions tolerable by life (\#7). Meteorites with and without indigenous PAHs were used as positive (\#1) and negative controls and blanks (\#2; McKay et al., 1996). These controls also helped establish that the meteorite mineralogy was indigenous to Mars.

Cell-like morphologies: The Mg-Fe-carbonate globules were deemed to have formed on Mars: they underwent shock faulting that could not have happened once on Earth. The carbon $\left(\delta^{13} \mathrm{C}=+42 \%\right)$ and oxygen isotopic fractionations exclude terran contamination (\#2), even though ALH84001 was found $\sim 13,000$ years after its fall in Antarctica. The globules' flattened morphologies, reminiscent of cells (Martel et al., 2012), suggested formation within fractures. Central textures in the globules were found consistent with biogenic calcium carbonate on Earth, but also with partial dissolution. The temperature of formation was inconsistently found to be $0-80^{\circ} \mathrm{C}$ from $\mathrm{C}$ and $\mathrm{O}$ isotopic compositions but above $650^{\circ} \mathrm{C}$ based on the cation composition and lack of hydrated minerals (McKay et al., 1996). It is still debated (Steele et al., 2007; Martel et al., 2012, and references therein).

Complex organics: The PAHs ( $>150$ to several hundred amu) include purely aromatic molecules and aromatics with alkyl chains. The PAH distribution was interpreted as possibly resulting from early degradation of biomolecules (McKay et al., 1996), but also with abiotic hydrothermalism (\#6) on Mars or in Mars impactors (Anders et al., 1996; Becker et al., 1997; Steele et al., 2007), or even as interstellar matter infall (Martel et al., 2012, and references therein). 
Terran contamination was estimated at only sub-part-perbillion levels, and to consist of compounds containing more alkyl chains and heteroatoms than observed. Furthermore, the concentration of PAHs increased with increasing depth, and was below detection in ALH84001's fusion crust, consistently with volatilization upon atmospheric entry (\#2).

Isotopic fractionations: Unlike in the carbonate globules, the PAH carbon is isotopically light and consistent with all interpretations (Becker et al., 1997, and references therein; Allen et al., 2006).

Colocated oxidant and reductant: Carbonates were associated with indigenous sulfide, possibly greigite $\left(\mathrm{Fe}_{3} \mathrm{~S}_{4}\right)$, colocated with a more oxidized form of iron, magnetite $\left(\mathrm{Fe}_{3} \mathrm{O}_{4}\right)$. However, it was objected that these minerals can coprecipitate abiotically at high $\mathrm{pH}$ (Anders et al., 1996; McKay et al., 1996). Both, especially magnetite particles, were found morphologically similar to biogenic minerals (McKay et al., 1996), but not convincingly (Anders et al., 1996; Martel et al., 2012, and references therein): for example, magnetite particles, which are used in biological magnetic sensing, feature in only a small subset of the tree of life (Nealson and Cox, 2002). Sulfur was not found to be fractionated differently than in other meteorites; meteorite $\mathrm{S}$ fractionations are within the broader ranges of biogenic S on Earth (Anders et al., 1996).

The evidence for these features being contamination-free (\#2) was generally found convincing (Anders et al., 1996; Steele et al., 2007, and references therein; Martel et al., 2012; but see Becker et al. 1997). McKay et al. (1996) interpreted the overall evidence as biogenic but acknowledged that each observation could have an abiotic interpretation (\#6). Many others favored an abiotic origin for each feature (\#8; Anders et al., 1996; Becker et al., 1997; García Ruiz et al., 2002; Steele et al., 2007, and references therein; Martel et al., 2012). Rule K would lead to the same conclusion. As stated by Becker et al. (1997), a biogenic interpretation would require additional evidence, for example for specific organic structures enhancing function such as chirality in amino acids (Rule D). ALH84001 contained amino acids detected by high-performance liquid chromatography (HPLC) (Bada et al., 1998), but these were terran contamination, which occurred even in martian meteorites recovered quickly after their fall (Glavin et al., 1999).

\subsection{Archean lipid biomarkers}

Beyond the interpretation of combined evidence for biological features, this case illustrates the management of contamination control in life detection (\#2). It is therefore informative for future sample return (Section 6).

Specific hopanes and steranes, the degradation products of cellular membrane lipids (hopanoids and sterols), seem to originate respectively mainly from cyanobacteria, which are prime oxygenic phototrophs in the history of life on Earth (Summons et al., 1999), and by eukaryotes, which require molecular oxygen (Brocks et al., 1999, 2003b). These complex compounds have no obvious abiotic source (\#6). They are relatively metastable (\#5) and can be biomarkers for these organisms where morphologies are too degraded. This can allow quantification of the importance of cyanobacteria and eukaryotes through geological time, related to changes in atmospheric oxygen (Brocks et al., 2003b; French et al., 2015). Hopane and sterane detections meeting criteria \#1, 3, 4, and 7 suggested that oxygenic cyanobacteria and eukaryotes may have arisen in the Archean, much earlier than previously thought (Brocks et al., 1999, 2003b; Summons et al., 1999).

Lipid biomarkers are usually sought in natural samples that undergo lipid extraction, derivatization, and analysis by gas chromatography-mass spectrometry. Biomarker studies have to establish that the biomarkers were syngenetic with their enclosing rock (not only indigenous to the rock but that they co-originated with it) based on several requirements (Brocks et al., 1999, 2003a; Summons et al., 1999). The rocks had to have experienced only slight metamorphism $\left(\leq 150^{\circ} \mathrm{C}\right)$ so lipid biomarkers would be preserved (\#5). They had to host abundant kerogen $(<1-1000 \mathrm{ppm})$ associated with those lipids as evidence of the rest of now-degraded biomass. This association had to be strengthened by isotopic analyses of carbon in the kerogen and lipids. Ensuring a lack of contamination from younger sources (\#2) required sampling rocks far $(>100 \mathrm{~km})$ from younger oil-prone rocks, and with biomarker contents that did not decrease from the outside in.

Among these requirements, the isotopic evidence yielded conflicting results (Brocks et al., 1999, 2003b). Carbon from extracted biomarkers was isotopically heavier $\left(\delta^{13} \mathrm{C} \approx-27 \%\right.$ ) than surrounding kerogen $(-39 \%)$ in older Archean rocks, but typically $1-3 \%$ lighter than kerogen in younger Proterozoic rocks. Two explanations were proposed. The $\delta^{13} \mathrm{C}$ of kerogen may have increased over time, owing to a decrease in the contribution to kerogen from methanotrophs $\left(\delta^{13} \mathrm{C} \approx-80 \%\right.$ ) relative to the phototrophs that sourced the biomarkers $\left(\delta^{13} \mathrm{C} \approx-26 \%\right.$; Brocks et al., 1999, 2003b). Alternatively, biomarkers heavier than indigenous kerogen were contaminants, implanted either naturally or during sampling, storage, or analysis (\#2).

Extreme care was taken to prevent such contamination (Brocks et al., 1999, 2003a, 2003b), which had plagued similar studies in the 1960s (Brocks et al., 2003a, and references therein). The samples were separated from younger rocks by tens of kilometers of impermeable rock. Lipid contents scaled with less mobile kerogen abundances even among closely separated samples, supporting an indigenous origin. Measurement of non-hopane/sterane lipids typical of younger life (e.g., plants) helped assess any natural contamination. Sampling was as clean as possible but required the use of lipidbearing materials (drilling oil, diesel). Samples underwent multiple dichloromethane solvent rinses analyzed by chromatography; only those with clean rinses were broken open for extraction of interior material. To reduce cross-contamination, samples were processed in order of increasing kerogen content and occasionally interspersed with procedural blanks.

Despite these measures, in situ microscale isotopic measurements with nanoscale secondary ion mass spectrometry (NanoSIMS), bypassing the need for extraction and derivatization, yielded equally low $\delta^{13} \mathrm{C}$ values for both Archean kerogen and biomarkers but showed that oil in younger veins had higher $\delta^{13} \mathrm{C}$, favoring the interpretation of natural or human contamination (Rasmussen et al., 2008). Moreover, measured hopane and sterane abundances increased outward in core samples (Brocks, 2011). Contamination was confirmed by analyses of cores collected with hydrocarbonclean protocols, in which hopanes and steranes were either not detected or found below blank and negative control levels, even though those rocks bore indigenous kerogen (French et al., 2015). Thus, contamination was attributed to 
sample collection methods, invalidating previous evidence for oxygenic cyanobacteria and eukaryotes in the Archean (e.g., Brocks et al., 1999, 2003b; Summons et al., 1999).

\subsection{Lake Vostok accretion ice}

This is an example of successful life detection in a setting analogous to subsurface liquid water on icy worlds. DNA was detected, compellingly indicating biology (Rule C). Had this Earth-centric feature not been found, life would have still been detected by the combination of cell-like morphologies and HPLC analyses to find homochirality in amino acids (Rule D). Contamination control and assessments convincingly suggested that this biology is indigenous.

Subglacial Lake Vostok in Antarctica, discovered in the mid-1970s by airborne surveys, lies below $\sim 4 \mathrm{~km}$ of water ice. It may have been isolated from surface input for $\sim 0.5-15$ million years (Kapitsa et al., 1996; Petit et al., 1999; Siegert et al., 2003), although it likely receives input from glacial flow (Christner et al., 2001). Most overlying ice was deposited by atmospheric precipitation, but the lower $200 \mathrm{~m}$ is accretion ice resulting from decompression freezing of lake water (Karl et al., 1999; Christner et al., 2006, and references therein). Microorganisms were detected in the accretion ice (Abyzov et al., 1998; Karl et al., 1999; Priscu et al., 1999) and inferred to be indigenous to the lake. At the time, the lake itself was not sampled to avoid opening a path of exchange with the rest of Earth's biosphere (Christner et al., 2001, 2006).

The drilling procedures did not control for chemical and biological contamination of the ice core samples (Karl et al., 1999). However, stringent measures were taken to remove surficial contamination and avoid further contamination in the laboratory (\#2). Exterior surfaces were decontaminated by controlled melting and rinsing with extremely pure water (Karl et al., 1999; Christner et al., 2001, 2006; Bulat et al., 2004). Rinse water and drilling fluid were analyzed by gas chromatography-mass spectrometry (Christner et al., 2006) or sequencing (Bulat et al., 2004). Beyond clean laboratory procedures, the laboratories used by Priscu et al. (1999) and Bulat et al. (2004) had never been used to grow or process biological samples. Negative and positive controls were used and replicate analyses performed (\#1-3; Priscu et al., 1999; Christner et al., 2001, 2006). Christner et al. (2006) spiked analyzed cores with chemical and biological markers to assess laboratory contamination.

Cell morphologies were observed at levels down to $<10^{3}$ cells $\mathrm{mL}^{-1}$ (\#1) by optical (using DNA stains), SEM-EDS, and flow cytometry; staining unambiguously detected life (\#8; Rule C). Biomarkers were measured by antibody-based assays: lipopolysaccharides were detected, but ATP was below detection limit (\#1), consistently with low concentrations expected from cell and lipopolysaccharide abundances (Karl et al., 1999). Amino acid contents, measured with HPLC, scaled with organic carbon abundances (Christner et al., 2006). Labeled nutrient addition showed active metabolism in some core samples (Karl et al., 1999; Christner et al., 2006), but not all (Priscu et al., 1999). Ion chromatography and inductively coupled plasma mass spectrometry analyses provided further insight into possible metabolic pathways. Cells were later cultured (Christner et al., 2001).

DNA extracted and amplified by polymerase chain reaction (PCR) and analyzed by terminal restriction fragment length polymorphism (T-RFLP) revealed a low genetic diversity (Priscu et al., 1999; Christner et al., 2006). The 16S rRNA gene of isolated bacterial colonies was also sequenced (Christner et al., 2001). Of the phylotypes identified, one was found not to exist on any material used in sampling and analysis, placing a conservative lower limit on indigenous life (Bulat et al., 2004).

\subsection{Methane on Mars}

While not a direct attempt to detect life, the search for methane in the martian atmosphere informs remote sensing of exoplanet atmospheres for potentially biogenic gases. On Mars, sources of methane could be either abiotic (e.g., geothermal, geochemical, exogenic) or biogenic (\#6; Formisano et al., 2004; Atreya et al., 2007; Webster et al., 2015; Oehler and Etiope, 2017).

Methane gas at $<5-30 \mathrm{ppb}$ levels was reported in near-IR spectra of Mars acquired either from the ground (Krasnopolsky et al., 2004; Mumma et al., 2009) or martian orbit (Formisano et al., 2004). The observation of Krasnopolsky et al. (2004) was not repeated because the instrument was decommissioned, but Mumma et al. (2009) performed many such observations over several martian years with several telescopes (\#3).

Contamination from solar, martian, and terran spectral features was mitigated (\#2). To untangle martian from terran methane absorption in ground-based spectra, Mars was observed when its spectral features were Doppler-shifted relative to Earth's. Martian methane absorption still had to be searched as tiny overprints over Earth's much stronger methane and water features (Krasnopolsky et al., 2004; Mumma et al., 2009). Because these observations were subject to contamination (\#2), near limits of detection (\#1), and perhaps even inconsistent with what is known of the workings of Mars (\#4), doubt was cast on these detections (e.g., Zahnle et al., 2011).

Additional detections were reported; some contradicting others (Webster et al., 2015, and references therein). Among these, methane was detected from Mars' surface at sub-part-per-billion mean levels interspersed with episodic part-per-billion-level measurements. Contamination by the MSL rover was ruled out (Webster et al., 2015) but debated (Zahnle, 2015).

Methane on Mars is thought to be lost by photochemistry in $\sim 300$ years. The source rate yielding $10 \mathrm{ppb}$ of methane at steady state (\#5) was found achievable by abiotic geological processes (Oehler and Etiope, 2017) or a methanogenic biomass much lower than measurable by the Viking GC-MS (Biemann et al., 1977; Krasnopolsky et al., 2004), but not by exogenic input (Formisano et al., 2004; Krasnopolsky et al., 2004; Atreya et al., 2007). Methane should be globally mixed in $<1$ year (Krasnopolsky et al., 2004). Therefore, observed abundance variations (Formisano et al., 2004; Mumma et al., 2009; Webster et al., 2015) were attributed to seasonal changes and spatially discrete sources or sinks above photochemical destruction. Sinks could include abiotic oxidation by the regolith (Section 5.1; Mumma et al., 2009).

The debate on detecting and interpreting methane on Mars illustrates the difficulty of remote life detection in and beyond the Solar System (Seager and Bains, 2015). The knowledge of abiotic sources and sinks remains incomplete 
even for methane on Earth (Bradley, 2016; McCollom, 2016). These may be distinguished from biology by measuring isotopes (Krasnopolsky et al., 2004; Young et al., 2017) and abundance patterns among hydrocarbon gases (Allen et al., 2006). However, in our example decision framework, these additional lines of evidence do not eliminate all abiotic hypotheses (Rule J). It may be that life is remotely detectable only through spectral evidence for pigments (Rule B), strengthened by isotopic and compositional measurements and, perhaps, observations of organic compounds such as PAHs. For methane on Mars, the next insights may come from the ExoMars Trace Gas Orbiter (Korablev et al., 2015; Vandaele et al., 2015).

\section{Application to Future Attempts at Life Detection}

Mars, icy moons, and several exoplanets are targeted by life-detection mission concepts under study. Having learned from past attempts, all would involve instruments to detect several Ladder features. The most optimistic scenarios (all detectable features would be seen) are shown in Table 6 . The life-detection result according to the example decision framework of Section 4 is shown in the bottom row: in this framework, most missions could indeed exclude abiotic interpretations and detect life.

The ExoMars rover (Goesmann et al., 2017) could do so if its Mars Organic Molecule Analyzer (MOMA) GC-MS

Table 6. Application of the Simplistic Decision Rules of Tables 3 and 4 to Future Measurements That May Lead to a Claim of Life Detection

\begin{tabular}{|c|c|c|c|c|c|c|c|c|}
\hline Ladder Rung & Feature & Measurement & $\begin{array}{l}\text { Any } \\
\text { sample } \\
\text { return }\end{array}$ & $\begin{array}{l}\text { ExoMars } \\
\text { Rover }^{\text {a }}\end{array}$ & $\begin{array}{l}\text { Europa } \\
\text { Lander }{ }^{b}\end{array}$ & $\begin{array}{l}\text { Enceladus } \\
\text { plume in } \\
\text { situ }\end{array}$ & $\mid \begin{array}{c}\text { Titan Saturn } \\
\text { System } \\
\text { Mission }\end{array}$ & $\begin{array}{l}\text { Exoplanet } \\
\text { atmosphere } \\
\text { sensing }\end{array}$ \\
\hline $\begin{array}{l}\text { Darwinian } \\
\text { Evolution } \\
\end{array}$ & $\begin{array}{l}\text { Changes in inheritable traits in } \\
\text { response to selective pressures }\end{array}$ & Not possible & & & & & & $\mathrm{N} / \mathrm{A}$ \\
\hline \begin{tabular}{|c|} 
Growth \& \\
Reproduction
\end{tabular} & $\begin{array}{c}\text { Concurrent life stages or identifiable } \\
\text { reproductive form }\end{array}$ & $\begin{array}{l}\text { Cell(-like?) structures in } \\
\text { multiple stages }\end{array}$ & 1 & & 1 & & & $N / A$ \\
\hline \multirow{3}{*}{ Metabolism } & $\begin{array}{l}\text { Major element or isotope } \\
\text { fractionations indicative of } \\
\text { metabolism }\end{array}$ & $\begin{array}{c}\text { Deviation from abiotic } \\
\text { fractionation controlled by } \\
\text { thermodynamic } \\
\text { equilibrium and/or kinetics }\end{array}$ & 1 & MOMA & 1 & 1 & 1 & 1 \\
\hline & Response to substrate addition & $\begin{array}{c}\text { Waste output (compound, } \\
\text { heat) }\end{array}$ & 1 & & & & & $\mathrm{~N} / \mathrm{A}$ \\
\hline & Co-located reductant and oxidant & $\begin{array}{c}\text { Deviation from abiotic } \\
\text { equilibrium and/or kinetics }\end{array}$ & 1 & MicrOmega & 1 & & 1 & 1 \\
\hline \multirow{4}{*}{$\begin{array}{l}\text { Functional } \\
\text { molecules }\end{array}$} & $\begin{array}{l}\text { Polymers that support information } \\
\text { storage and transfer for terran life } \\
\text { (DNA, RNA) }\end{array}$ & Abundance & 1 & & & & 1 & $\mathrm{~N} / \mathrm{A}$ \\
\hline & \multirow{2}{*}{$\begin{array}{l}\text { Structural preferences in organic } \\
\text { molecules (non-random and } \\
\text { enhancing function) }\end{array}$} & \begin{tabular}{|c|}
$\begin{array}{c}\text { Polymer with repeating } \\
\text { charge }\end{array}$ \\
\end{tabular} & 1 & & & & & $\mathrm{~N} / \mathrm{A}$ \\
\hline & & \begin{tabular}{|c|} 
Enantiomeric excess $>$ \\
$20 \%$ in multiple amino acid \\
types
\end{tabular} & 1 & MOMA & 1 & & 1 & $\mathrm{~N} / \mathrm{A}$ \\
\hline & $\begin{array}{l}\text { Pigments as evidence of non- } \\
\text { random chemistries }\end{array}$ & \begin{tabular}{|c|}
$\begin{array}{c}\text { Spectral feature and/or } \\
\text { color }\end{array}$ \\
\end{tabular} & 1 & MicrOmega & 1 & & 1 & 1 \\
\hline \multirow{3}{*}{$\begin{array}{c}\text { Potential } \\
\text { biomolecule } \\
\text { components }\end{array}$} & $\begin{array}{c}\text { Organics not found abiotically (e.g., } \\
\text { hopanes, ATP, histidine) }\end{array}$ & Presence & 1 & MOMA & 1 & 1 & 1 & $\mathrm{~N} / \mathrm{A}$ \\
\hline & $\begin{array}{l}\text { Complex organics (nucleic acid } \\
\text { oligomers, peptides, PAH) }\end{array}$ & Presence & 1 & $\begin{array}{l}\text { MOMA, } \\
\text { RLS }\end{array}$ & 1 & 1 & 1 & $N / A^{e}$ \\
\hline & \begin{tabular}{|c|} 
Monomeric units of biopolymers \\
(nucleobases, amino acids, lipids for \\
compartmentalization)
\end{tabular} & Presence & 1 & MOMA & 1 & 1 & 1 & 1 \\
\hline \multirow{2}{*}{$\begin{array}{c}\text { Potential } \\
\text { metabolic } \\
\text { byproducts }\end{array}$} & \begin{tabular}{|c|} 
Distribution of metals \\
\end{tabular} & \begin{tabular}{|c|} 
Presence \\
\end{tabular} & 1 & & & & & $\mathrm{~N} / \mathrm{A}$ \\
\hline & Patterns of complexity (organics) & \begin{tabular}{|c|} 
Deviation from abiotic \\
equilibrium and/or kinetics \\
\end{tabular} & 1 & MOMA & 1 & 1 & 1 & $\mathrm{~N} / \mathrm{A}$ \\
\hline Biofabrics & Textures & \begin{tabular}{|c|} 
Biologically mediated \\
morphologies, preferably \\
with co-located \\
composition
\end{tabular} & 1 & MicrOmega & 1 & & & $\mathrm{~N} / \mathrm{A}$ \\
\hline \multicolumn{3}{|c|}{ Life Detection Result } & 1 & 1 & 1 & 0 & 1 & 1 \\
\hline
\end{tabular}

Outcomes most indicative of life given a planned payload are indicated. Any sample return would have access to the entire suite of techniques used in previous life-detection investigations (Section 5).

${ }^{\mathrm{a}}$ Goetz et al. (2016), Goesmann et al. (2017). ${ }^{\mathrm{b}}$ Hand et al. (2017). ${ }^{\mathrm{C}}$ Lunine et al. (2015), Reh et al. (2016). ${ }^{\mathrm{d}}$ Spencer and Niebur (2010). ${ }^{\mathrm{e}}$ Except perhaps for organic compounds such as PAHs. 
detects both large enantiomeric excesses and patterns in the distribution of organics (Rule $\mathrm{H}$ ) or if the MicrOmega imager sees spectral evidence for complex pigments (Rule B). The latter case is unlikely given current orbital and surface evidence. However, the former features could be detected in drilled subsurface samples, where organics would be less subject to oxidation than at the surface. The lander of the Titan Saturn System Mission concept (Spencer and Niebur, 2010) could have the same capabilities (save for drilling and a micro-imager), leading to similar scenarios.

The Europa lander studied by Hand et al. (2017) could have the added ability, with a microscope instrument, to detect cell-like morphologies down to a level of 100 cells $\mathrm{cm}^{-3}, 0.2 \mu \mathrm{m}$ in size. This could allow two additional lifedetection scenarios: cell-like morphologies seen at different growth or reproductive stages with the strawman microscope, together with large enantiomeric excesses (Rule D) and/or with patterns among organics (Rule E) detected with the planned separation-mass spectrometer instrument.

A mission sampling the plume of Enceladus during flythroughs, such as the proposed Enceladus Life Finder (Lunine et al., 2015; Reh et al., 2016), could rely on mass spectrometry without a separation capability or microscope. This could enable quantification of isotopes, simple and complex organics, and patterns among them. Without information on chirality or morphology, these measurements may not suffice to preclude complex abiotic (prebiotic) chemistry (Rule J). One could envision situations in which it might, such as the detection of extreme disequilibrium or very complex molecules. Both lend themselves to more quantitative analysis than captured in our simplistic decision framework, emphasizing the needs to quantify probabilities of the validity of abiotic null hypotheses for each measurement and to define thresholds for their rejection.

Regarding remote life detection on an exoplanet, the strongest evidence (assuming this life is not intelligent) could come from a globally distributed pigment with a unique spectral signature that cannot be confused with other materials (Rule B). As with Earth (Section 5.3), this would likely require acquiring spatially resolved reflectance spectra, a feat which remains many decades away (Schneider et al., 2010). More likely, detailed atmospheric compositions would be measured, perhaps even isotopic chemistry, which would require spectra of very high sensitivity and resolution. These could be interpreted more quantitatively with a measure of disequilibrium from an abiotic background (KrissansenTotton et al., 2018). As stated by Seager and Bains (2015), "We must accept that with remote observations, our inference of the existence of life on another world will be probabilistic, an estimate of our confidence that life is the only reasonable explanation of the atmospheric chemistry of an exoplanet." In other words, it will be challenging to accumulate sufficient observational data to bring the probability of the null hypothesis below the rejection threshold.

Finally, sample return from Mars, an icy moon, or other Solar System locales could provide access to the entire suite of Ladder features, aside perhaps from Darwinian evolution. This could lead to any of seven scenarios of life detection (Rules B through H). Analyses of Lake Vostok ice have shown that life can be detected in this way (Section 5.6). Successful analysis of Earth-specific nucleic acids did not make analyses of structures and patterns among organics necessary, but such analyses, combined with cell-like morphologies, would have also led to life detection.

Sample return analyses could be especially prone to contamination by Earth's ubiquitous biosphere. Mitigation strategies were assessed for Mars 2020 (Summons et al., 2014). Recommendations included using numerous blanks (e.g., witness plates carried through every incremental stage of mission development and operations) and standards. They also included building databases of chemical compounds and organisms akin to those used in previous life-detection investigations (Bulat et al., 2004; Summons et al., 2014), which boosted confidence in the past that indigenous material had been detected (Bulat et al., 2004; Freissinet et al., 2015).

\section{Conclusions}

The past 20 years have seen renewed vigor in the exploration of our solar system, an explosion in exoplanet discoveries, and tremendous progress in understanding life in its planetary context. This has made it possible to formulate the first life-detection mission concepts since Viking. To aid in mission planning, the Ladder of Life Detection synthesizes our current knowledge of life, the methods available to detect it, and lessons learned from past attempts.

Our example decision framework suggests a possible use of the Ladder to discuss which combinations of evidence might preclude any abiotic interpretation, the community standard for life detection. This basic framework must be improved by explicitly quantifying probabilistic values for the likelihood that a set of measurements cannot be ascribed to contamination or abiotic processes in realistic scenarios, rather than simply assuming the binary result that this probability is above or below a rejection threshold. Simple as it is, this version is an accurate lens through which to examine past attempts at detecting life. It also suggests that ongoing development in instrumentation, mission formulation, and contamination and planetary protection measures could indeed enable the detection of life, if present. Past experience suggests that these renewed attempts will greatly improve our knowledge of life as a cosmic phenomenon.

\section{Acknowledgments}

We thank Jim Green, who spurred the development of this tool and its organization as a ladder, as well as Jonathan Lunine, Astrobiology Editor Sherry Cady, Associate Editor Chris McKay, and four anonymous reviewers for helpful comments and suggestions. M.N. acknowledges support from the NASA Postdoctoral Management Program administered by Universities Space Research Association. This research was in part carried out at the Jet Propulsion Laboratory, California Institute of Technology, under a contract with the National Aeronautics and Space Administration. The community is welcome to suggest improvements to the Ladder at https://astrobiology.nasa.gov/research/life-detection/ladder.

\section{Author Disclosure Statement}

No competing financial interests exist.

\section{References}

Abyzov, S.S., Mitskevich, I.N., and Poglazova, M.N. (1998) Microflora of the deep glacier horizons of central Antarctica. Microbiology 67:451-458. 
Aksyonov, S.A. and Williams, P. (2001) Impact desolvation of electrosprayed microdroplets - a new ionization method for mass spectrometry of large biomolecules. Rapid Commun Mass Spectrom 15:2001-2006.

Allen, M., Sherwood Lollar, B., Runnegar, B., Oehler, D.Z., Lyons, J.R., Manning, C.E., and Summers, M.E. (2006) Is Mars alive? Eos 87:433-439.

Anders, E., Shearer, C.K., Papike, J.J., Bell, J.F., Clemett, S.J., Zare, R.N., McKay, D.S., Thomas-Keprta, K.L., Romanek, C.S., Gibson, E.K., and Vali, H. (1996) Evaluating the evidence for past life on Mars. Science 274:2119-2125.

Anderson, D.M., Biemann, K., Orgel, L.E., Oro, J., Owen, T., Shulman, G.P., Toulmin, P., and Urey, H.C. (1972) Mass spectrometric analysis of organic compounds, water and volatile constituents in the atmosphere and surface of Mars: the Viking Mars lander. Icarus 16:111-138.

Armbruster, D.A. and Pry, T. (2008) Limit of blank, limit of detection and limit of quantitation. Clin Biochem Rev 29: S49-S52.

Atreya, S.K., Mahaffy, P.R., and Wong, A.S. (2007) Methane and related trace species on Mars: origin, loss, implications for life, and habitability. Planet Space Sci 55:358-369.

Bada, J.L. and McDonald, G.D. (1995) Amino acid racemization on Mars: implications for the preservation of biomolecules from an extinct martian biota. Icarus 114:139-143.

Bada, J.L., Wang, X.S., Poinar, H.N., Pääbo, S., and Poinar, G.O. (1994) Amino acid racemization in amber-entombed insects: implications for DNA preservation. Geochim Cosmochim Acta 58:3131-3135.

Bada, J.L., Glavin, D.P., McDonald, G.D., and Becker, L. (1998) A search for endogenous amino acids in martian meteorite ALH84001. Science 279:362-365.

Bada, J.L., Wang, X.S., and Hamilton, H. (1999) Preservation of key biomolecules in the fossil record: current knowledge and future challenges. Philos Trans R Soc Lond B Biol Sci 354:77-87.

Beauchamp, P. and Belz, A. (2013) Assessing planetary protection and contamination control technologies for planetary science missions. In 2013 IEEE Aerospace Conference, IEEE, Piscataway, NJ, doi:10.1109/AERO.2013.6497395.

Becker, L., Glavin, D.P., and Bada, J.L. (1997) Polycyclic aromatic hydrocarbons (PAHs) in Antarctic martian meteorites, carbonaceous chondrites, and polar ice. Geochim Cosmochim Acta 61:475-481.

Bedrossian, M., Lindensmith, C., and Nadeau, J.L. (2017) Digital holographic microscopy, a method for detection of microorganisms in plume samples from Enceladus and other icy worlds. Astrobiology 17:913-925.

Benner, S.A. (2010) Defining life. Astrobiology 10:1021-1030.

Benner, S.A. (2017) Detecting Darwinism from molecules in the Enceladus plumes, Jupiter's moons, and other planetary water lagoons. Astrobiology 17:840-851.

Benner, S.A., Devine, K.G., Matveeva, L.N., and Powell, D.H. (2000) The missing organic molecules on Mars. Proc Natl Acad Sci USA 97:2425-2430.

Biemann, K., Oro, J., Toulmin, P., Orgel, L.E., Nier, A.O., Anderson, D.M., Simmonds, P.G., Flory, D., Diaz, A.V., Rushneck, D.R., Biller, J.E., and Lafleur, A.L. (1977) The search for organic substances and inorganic volatile compounds in the surface of Mars. J Geophys Res 82:4641-4658.

Blackmond, D.G. (2011) The origin of biological homochirality. Philos Trans R Soc Lond B Biol Sci 366:2878-2884.

Botta, O., Bada, J.L., Gomez-Elvira, J., Javaux, E., Selsis, F., and Summons, R. (2008) Strategies of Life Detection, Space Science Series of ISSI, Vol. 25, Springer, New York.
Bradley, A.S. (2016) The sluggish speed of making abiotic methane. Proc Natl Acad Sci USA 113:13944-13946.

Brasier, A.T., Rogerson, M.R., Mercedes-Martin, R., Vonhof, H.B., and Reijmer, J.J.G. (2015) A test of the biogenicity criteria established for microfossils and stromatolites on Quaternary tufa and speleothem materials formed in the "Twilight Zone" at Caerwys, UK. Astrobiology 15:883-900.

Brasier, M.D., Green, O.R., Jephcoat, A.P., Kleppe, A.K., Van Kranendonk, M.J., Lindsay, J.F., Steele, A., and Grassineau, N.V. (2002) Questioning the evidence for Earth's oldest fossils. Nature 416:76-81.

Brasier, M.D., Antcliffe, J., Saunders, M., and Wacey, D. (2015) Changing the picture of Earth's earliest fossils (3.5$1.9 \mathrm{Ga})$ with new approaches and new discoveries. Proc Natl Acad Sci USA 112:4859-4864.

Breslow, R. and Cheng, Z.L. (2009) On the origin of terrestrial homochirality for nucleosides and amino acids. Proc Natl Acad Sci USA 106:9144-9146.

Breslow, R. and Levine, M.S. (2006) Amplification of enantiomeric concentrations under credible prebiotic conditions. Proc Natl Acad Sci USA 103:12979-12980.

Brocks, J.J. (2011) Millimeter-scale concentration gradients of hydrocarbons in Archean shales: live-oil escape or fingerprint of contamination? Geochim Cosmochim Acta 75:3196-3213.

Brocks, J.J., Logan, G.A., Buick, R. and Summons, R.E. (1999) Archean molecular fossils and the early rise of eukaryotes. Science 285:1033-1036.

Brocks, J.J., Buick, R., Logan, G.A., and Summons, R.E. (2003a) Composition and syngeneity of molecular fossils from the 2.78 to 2.45 billion-year-old Mount Bruce Supergroup, Pilbara Craton, Western Australia. Geochim Cosmochim Acta 67: 4289-4319.

Brocks, J.J., Buick, R., Summons, R.E., and Logan, G.A. (2003b) A reconstruction of Archean biological diversity based on molecular fossils from the 2.78 to 2.45 billion-year-old Mount Bruce Supergroup, Hamersley Basin, Western Australia. Geochim Cosmochim Acta 67:4321-4335.

Brown, P., Rau, E.H., Lemieux, P., Johnson, B.K., Bacote, A.E., and Gajdusek, D.C. (2004) Infectivity studies of both ash and air emissions from simulated incineration of scrapiecontaminated tissues. Environ Sci Technol 38:6155-6160.

Bulat, S.A., Alekhina, I.A., Blot, M., Petit, J.R., De Angelis, M., Wagenbach, D., Lipenkov, V.Ya., Vasilyeva, L.P., Wloch, D.M., Raynaud, D., and Lukin, V.V. (2004) DNA signature of thermophilic bacteria from the aged accretion ice of Lake Vostok, Antarctica: implications for searching for life in extreme icy environments. International Journal of Astrobiology 3, doi:10.1017/S1473550404001879.

Burchell, M.J., Bowden, S.A., Cole, M., Price, M.C., and Parnell, J. (2014) Survival of organic materials in hypervelocity impacts of ice on sand, ice, and water in the laboratory. Astrobiology 14:473-485.

Cable, M.L., Hörst, S.M., Hodyss, R., Beauchamp, P.M., Smith, M.A., and Willis, P.A. (2012) Titan tholins: simulating Titan organic chemistry in the Cassini-Huygens era. Chem Rev 112: 1882-1909.

Cady, S.L. and Noffke, N. (2009) Geobiology: evidence for early life on Earth and the search for life on other planets. GSA Today 19:4-10.

Cady, S.L., Farmer, J.D., Grotzinger, J.P., Schopf, J.W., and Steele, A. (2003) Morphological biosignatures and the search for life on Mars. Astrobiology 3:351-368.

Cavalazzi, B., Westall, F., Cady, S.L., Barbieri, R., and Foucher, F. (2011) Potential fossil endoliths in vesicular pillow 
basalt, Coral Patch Seamount, eastern North Atlantic Ocean. Astrobiology 11:619-632.

Cavalazzi, B., Barbieri, R., Cady, S.L., George, A.D., Gennaro, S., Westall, F., Lui, A., Canteri, R., Rossi, A.P., Ori, G.G., and Taj-Eddine, K. (2012) Iron-framboids in the hydrocarbonrelated Middle Devonian Hollard Mound of the Anti-Atlas mountain range in Morocco: evidence of potential microbial biosignatures. Sedimentary Geology 263:183-193.

Chao, L. (2000) The meaning of life. BioScience 50:245-250.

Christner, B.C., Mosley-Thompson, E., Thompson, L.G., and Reeve, J.N. (2001) Isolation of bacteria and 16S rDNAs from Lake Vostok accretion ice. Environ Microbiol 3:570-577.

Christner, B.C., Royston-Bishop, G., Foreman, C.M., Arnold, B.R., Tranter, M., Welch, K.A., Lyons, W.B., Tsapin, A.I., Studinger, M., and Priscu, J.C. (2006) Limnological conditions in subglacial Lake Vostok, Antarctica. Limnol Oceanogr 51:2485-2501.

Chyba, C.F. and Phillips, C.B. (2002) Europa as an abode of life. Orig Life Evol Biosph 32:47-67.

Cleaves, H.J., Aubrey, A.D., and Bada, J.L. (2009) An evaluation of the critical parameters for abiotic peptide synthesis in submarine hydrothermal systems. Orig Life Evol Biosph 39:109-126.

Cole, D.R. and Chakraborty, S. (2001) Rates and mechanisms of isotopic exchange. Reviews in Mineralogy and Geochemistry 43:83-223.

Conrad, P.G. and Nealson, K.H. (2001) A non-Earthcentric approach to life detection. Astrobiology 1:15-24.

Corliss, J.B., Dymond, J., Gordon, L.I., Edmond, J.M., von Herzen, R.P., Ballard, R.D., Green, K., Williams, D., Bainbridge, A., Crane, K., and van Andel, T.H. (1979) Submarine thermal springs on the Galápagos Rift. Science 203:1073-1083.

Cronin, J.R. and Pizzarello, S. (1997) Enantiomeric excesses in meteoritic amino acids. Science 275:951-955.

Darwin, C. (1859) On the Origin of Species by Means of Natural Selection, or the Preservation of Favoured Species in the Struggle for Life, Ed. John Murray, London.

De Gregorio, B.T., Sharp, T.G., Flynn, G.J., Wirick, S., and Hervig, R.L. (2009) Biogenic origin for Earth's oldest putative microfossils. Geology 37:631-634.

Dick, S.J. (2006) NASA and the search for life in the Universe. Endeavour 30:71-75.

Dodd, M.S., Papineau, D., Grenne, T., Slack, J.F., Rittner, M., Pirajno, F., O'Neil, J., and Little, C.T. (2017) Evidence for early life in Earth's oldest hydrothermal vent precipitates. Nature 543:60-64.

Domagal-Goldman, S.D., Wright, K.E., Adamala, K., Arina de la Rubia, L., Bond, J., Dartnell, L.R., Goldman, A.D., Lynch, K., Naud, M.-E., Paulino-Lima, I.G., Singer, K., Walter-Antonio, M., Abrevaya, X.C., Anderson, R., Arney, G., Atri, D., Azúa-Bustos, A., Bowman, J.S., Brazelton, W.J., Brennecka, G.A., Carns, R., Chopra, A., Colangelo-Lillis, J., Crockett, C.J., DeMarines, J., Frank, E.A., Frantz, C., de la Fuente, E., Galante, D., Glass, J., Gleeson, D., Glein, C.R., Goldblatt, C., Horak, R., Horodyskyj, L., Kaçar, B., Kereszturi, A., Knowles, E., Mayeur, P., McGlynn, S., Miguel, Y., Montgomery, M., Neish, C., Noack, L., Rugheimer, S., Stüeken, E.E., Tamez-Hidalgo, P., Imari Walker, S., and Wong, T. (2016) The Astrobiology Primer v2.0. Astrobiology 16:561-653.

Eigenbrode, J.L. (2008) Fossil lipids for life-detection: A case study from the early Earth record. Space Sci Rev 135:161-185.

Elena, S.F. and Lenski, R.E. (2003) Microbial genetics: evolution experiments with microorganisms: the dynamics and genetic bases of adaptation. Nat Rev Genet 4:457-469.

Elsila, J.E., Glavin, D.P., and Dworkin, J.P. (2009) Cometary glycine detected in samples returned by Stardust. Meteorit Planet Sci 44:1323-1330.
Ezell, E.C. and Ezell, L.N. (1984) On Mars. Exploration of the Red Planet 1958-1978, NASA SP-4212, NASA, Washington, DC. Available online at https://history.nasa.gov/SP-4212/onmars.html

Farmer, J.D. and Des Marais, D.J. (1999) Exploring for a record of ancient martian life. J Geophys Res: Planets 104:26977-26995.

Formisano, V., Atreya, S., Encrenaz, T., Ignatiev, N., and Giuranna, M. (2004) Detection of methane in the atmosphere of Mars. Science 306:1758-1761.

Freissinet, C., Glavin, D.P., Mahaffy, P.R., Miller, K.E., Eigenbrode, J.L., Summons, R.E., Brunner, A.E., Buch, A., Szopa, C., Archer, P.D., Franz, H.B., Atreya, S.K., Brinckerhoff, W.B., Cabane, M., Coll, P., Conrad, P.G., Des Marais, D.J., Dworkin, J.P., Fairén, A.G., François, P., Grotzinger, J.P., Kashyap, S., ten Kate, I.L., Leshin, L.A., Malespin, C.A., Martin, M.G., MartinTorres, F.J., McAdam, A.C., Ming, D.W., Navarro-González, R., Pavlov, A.A., Prats, B.D., Squyres, S.W., Steele, A., Stern, J.C., Sumner, D.Y., Sutter, B., Zorzano, M.-P., and the MSL Science Team. (2015) Organic molecules in the Sheepbed mudstone, Gale Crater, Mars. J Geophys Res: Planets 120:495-514.

French, K.L., Hallmann, C., Hope, J.M., Schoon, P.L., Zumberge, J.A., Hoshino, Y., Peters, C.A., George, S.C., Love, G.D., Brocks, J.J., Buick, R., and Summons, R.E. (2015) Reappraisal of hydrocarbon biomarkers in Archean rocks. Proc Natl Acad Sci USA 112:5915-5920.

Friedrich, J.M., Wang, M.S., and Lipschutz, M.E. (2002) Comparison of the trace element composition of Tagish Lake with other primitive carbonaceous chondrites. Meteorit Planet Sci 37:677-686.

Fry, I. (2011) The role of natural selection in the origin of life. Orig Life Evol Biosph 41:3-16.

García Ruiz, J.M., Carnerup, A., Christy, A.G., Welham, N.J., and Hyde, S.T. (2002) Morphology: an ambiguous indicator of biogenicity. Astrobiology 2:353-369.

Georgiou, C.D. and Deamer, D.W. (2014) Lipids as universal biomarkers of extraterrestrial life. Astrobiology 14:541-549.

Glavin, D.P. and Dworkin, J.P. (2009) Enrichment of the amino acid L-isovaline by aqueous alteration on CI and CM meteorite parent bodies. Proc Natl Acad Sci USA 14:5487-5492.

Glavin, D.P., Bada, J.L., Brinton, K.L., and McDonald, G.D. (1999) Amino acids in the martian meteorite Nakhla. Proc Natl Acad Sci USA 96:8835-8838.

Glavin, D.P., Freissinet, C., Miller, K.E., Eigenbrode, J.L., Brunner, A.E., Buch, A., Sutter, B., Archer, P.D., Atreya, S.K., Brinckerhoff, W.B., Cabane, M., Coll, P., Conrad, P.G., Coscia, D., Dworkin, J.P., Franz, H.B., Grotzinger, J.P., Leshin, L.A., Martin, M.G., McKay, C.P., Ming, D.W., NavarroGonzález, R., Pavlov, A., Steele, A., Summons, R.E., Szopa, C., Teinturier, S., and Mahaffy, P.R. (2013) Evidence for perchlorates and the origin of chlorinated hydrocarbons detected by SAM at the Rocknest aeolian deposit in Gale Crater. J Geophys Res: Planets 118:1955-1973.

Goesmann, F., Brinckerhoff, W.B., Raulin, F., Goetz, W., Danell, R.M., Getty, S.A., Siljeström, S., Mißbach, H., Steininger, H., Arevalo, R.D., Jr., Buch, A., Freissinet, C., Grubisic, A., Meierhenrich, U.J., Pinnick, V.T., Stalport, F., Szopa, C., Vago, J.L., Lindner, R., Schulte, M.D., Brucato, J.R., Glavin, D.P., Grand, N., Li, X., van Amerom, F.H.W., and the MOMA Science Team. (2017) The Mars Organic Molecule Analyzer (MOMA) instrument: characterization of organic material in martian sediments. Astrobiology 17:655-685.

Goetz, W., Brinckerhoff, W.B., Arevalo, R., Freissinet, C., Getty, S., Glavin, D.P., Siljeström, S., Buch, A., Stalport, F., Grubisic, A., Li, X., Pinnick, V., Danell, R., van Amerom, 
F.H.W., Goesmann, F., Steininger, H., Grand, N., Raulin, F., Szopa, C., Meierhenrich, U., Brucato, J.R., and the MOMA Science Team. (2016) MOMA: the challenge to search for organics and biosignatures on Mars. International Journal of Astrobiology 15:239-250.

Grasby, S.E., Allen, C.C., Longazo, T.G., Lisle, J.T., Griffin, D.W., and Beauchamp, B. (2003) Supraglacial sulfur springs and associated biological activity in the Canadian High Arctic - signs of life beneath the ice. Astrobiology 3:583-596.

Gu, C., Somogyi, Á., Wysocki, V.H., and Medzihradszky, K.F. (1999) Fragmentation of protonated oligopeptides XLDVLQ ( $\mathrm{X}=\mathrm{L}, \mathrm{H}, \mathrm{K}$ or $\mathrm{R}$ ) by surface induced dissociation: additional evidence for the 'mobile proton' model. Anal Chim Acta 397: 247-256.

Hand, K.P., Murray, A.E., Garvin, J.B., Brinckerhoff, W.B., Christner, B.C., Edgett, K.S., Ehlmann, B.L., German, C.R., Hayes, A.G., Hoehler, T.M., Horst, S.M., Lunine, J.I., Nealson, K.H., Paranicas, C., Schmidt, B.E., Smith, D.E., Rhoden, A.R., Russell, M.J., Templeton, A.S., Willis, P.A., Yingst, R.A., Phillips, C.B., Cable, M.L., Craft, K.L., Hofmann, A.E., Nordheim, T.A., Pappalardo, R.P., and the Project Engineering Team. (2017) Europa Lander Study 2016 Report: Europa Lander Mission, JPL D-97667, NASA, Washington, DC. Available online at https://solarsystem.nasa.gov/docs/ Europa_Lander_SDT_Report_2016.pdf

Harman, C.E., Schwieterman, E.W., Schottelkotte, J.C., and Kasting, J.F. (2015) Abiotic $\mathrm{O}_{2}$ levels on planets around F, G, $\mathrm{K}$, and $\mathrm{M}$ stars: possible false positives for life? Astrophys $J$ 812, doi:10.1088/0004-637X/812/2/137.

Harvey, R.P. and McSween, H.Y. (1996) A possible hightemperature origin for the carbonates in the martian meteorite ALH84001. Nature 382:49-51.

Hecht, M.H., Kounaves, S.P., Quinn, R.C., West, S.J., Young, S.M.M., Ming, D.W., Catling, D.C., Clark, B.C., Boynton, W.V., Hoffman, J., DeFlores, L.P., Gospodinova, K., Kapit, J., and Smith, P.H. (2009) Detection of perchlorate and the soluble chemistry of martian soil at the Phoenix lander site. Science 325:64-67.

Hoehler, T.J. (2017) Biosignatures in the context of low energy flux [abstract 3556]. In Astrobiology Science Conference 2017, Lunar and Planetary Institute, Houston, LPI Contribution 1965.

Hoffman, B.M., Lukoyanov, D., Yang, Z.Y., Dean, D.R., and Seefeldt, L.C. (2014) Mechanism of nitrogen fixation by nitrogenase: the next stage. Chem Rev 114:4041-4062.

Horneck, G., Walter, N., Westall, F., Grenfell, J.L., Martin, W.F., Gomez, F., Leuko, S., Lee, N., Onofri, S., Tsiganis, K., Saladino, R., Pilat-Lohinger, E., Palomba, E., Harrison, J., Rull, F., Muller, C., Strazzulla, G., Brucato, J.R., Rettberg, P., and Capria, M.T. (2016) AstRoMap European Astrobiology Roadmap. Astrobiology 16:201-243.

Horowitz, N.H. (1976) The search for life in the Solar System. Acc Chem Res 9, doi:10.1021/ar50097a001.

Horowitz, N.H., Hubbard, J.S., and Hobby, G.L. (1972) The carbon-assimilation experiment: the Viking Mars lander. Icarus 16:147-152.

Horowitz, N.H., Hobby, G.L., and Hubbard, J.S. (1977) Viking on Mars: the carbon assimilation experiments. J Geophys Res 82:4659-4662.

House, C.H., Schopf, J.W., McKeegan, K.D., Coath, C.D., Harrison, T.M., and Stetter, K.O. (2000) Carbon isotopic composition of individual Precambrian microfossils. Geology 28:707-710.

H. Rept. 114-130. (2015, May 27) Commerce, Justice, Science, and Related Agencies Appropriations Bill, 2016. $114^{\text {th }}$ Con- gress, House of Representatives, Washington, DC. Available online at https://www.congress.gov/congressional-report/ 114th-congress/house-report/130/1

Hug, L.A., Baker, B.J., Anantharaman, K., Brown, C.T., Probst, A.J., Castelle, C.J., Butterfield, C.N., Hernsdorf, A.W., Amano, Y., Ise, K., Suzuki, Y., Dudek, N., Relman, D.A., Finstad, K.M., Amundson, R., Thomas, B.C., and Banfield, J.F. (2016) A new view of the tree of life. Nat Microbiol 1, doi:10.1038/nmicrobiol.2016.48.

Joyce, G. (1994) Foreword. In Origins of Life: The Central Concepts, edited by D.W. Deamer and G.R. Fleischaker, Jones \& Bartlett, Boston, pp xi-xii.

Jull, A.J.T., Beck, J.W., and Burr, G.S. (2000) Isotopic evidence for extraterrestrial organic material in the martian meteorite, Nakhla. Geochim Cosmochim Acta 64:3763-3772.

Kapitsa, A.P., Ridley, J.K., Robin, G.D.Q., Siegert, M.J., and Zotikov, I.A. (1996) A large deep freshwater lake beneath the ice of central East Antarctica. Nature 381:684-686.

Karl, D., Bird, D.F., Björkman, K., Houlihan, T., Shackelford, R., and Tupas, L. (1999) Microorganisms in the accreted ice of Lake Vostok, Antarctica. Science 286:2144-2147.

Kaur, H. and Halliwell, B. (1996) Measurement of oxidized and methylated DNA bases by HPLC with electrochemical detection. Biochem J 318:21-23.

Kiang, N.Y., Segura, A., Tinetti, G., Govindjee, Blankenship, R.E., Cohen, M., Siefert, J., Crisp, D., and Meadows, V.S. (2007) Spectral signatures of photosynthesis. II. Coevolution with other stars and the atmosphere on extrasolar worlds. Astrobiology 7:252-274.

Kidd, R.D., Noell, A., Kazarians, G., Aubrey, A.D., Scianmarello, N., and Tai, Y.C. (2015) Ion chromatography-on-a-chip for water quality analysis [ICES-2015-141]. In $45^{\text {th }}$ International Conference on Environmental Systems, Bellevue, WA.

Klein, H.P. (1978) The Viking biological experiments on Mars. Icarus 34:666-674.

Klein, H.P., Horowitz, N.H., Levin, G.V., Oyama, V.I., Lederberg, J., Rich, A., Hubbard, J.S., Hobby, G.L., Straat, P.A., Berdahl, B.J., Carle, G.C., Brown, F.S., and Johnson, R.D. (1976) The Viking biological investigation: preliminary results. Science 194:99-105.

Klussmann, M., Iwamura, H., Mathew, S.P., Wells, D.H., Pandya, U., Armstrong, A., and Blackmond, D.G. (2006) Thermodynamic control of asymmetric amplification in amino acid catalysis. Nature 441:621-623.

Knak Jensen, S.J., Skibsted, J., Jakobsen, H.J., ten Kate, I.L., Gunnlaugsson, H.P., Merrison, J.P., Finster, K., Bak, E., Iversen, J.J., Kondrup, J.C., and Nørnberg, P. (2014) A sink for methane on Mars? The answer is blowing in the wind. Icarus 236:24-27.

Korablev, O.I., Montmessin, F., Fedorova, A.A., Ignatiev, N.I., Shakun, A.V., Trokhimovskiy, A.V., Grigoriev, A.V., Anufreichik, K.A., and Kozlova, T.O. (2015) ACS experiment for atmospheric studies on "ExoMars-2016" orbiter. Solar System Research 49:529-537.

Kounaves, S.P., Carrier, B.L., O’Neil, G.D., Stroble, S.T., and Claire, M.W. (2014) Evidence of martian perchlorate, chlorate, and nitrate in Mars meteorite EETA79001: implications for oxidants and organics. Icarus 229:206-213.

Krasnopolsky, V.A., Maillard, J.P., and Owen, T.C. (2004) Detection of methane in the martian atmosphere: evidence for life? Icarus 172:537-547.

Krissansen-Totton, J., Olson, S., and Catling, D.C. (2018) Disequilibrium biosignatures over Earth history and implications for detecting exoplanet life. Science Advances 4: eaao5747, doi:10.1126/sciadv.aao5747. 
Lam, H., Oh, D.-C., Cava, F., Takacs, C.N., Clardy, J., de Pedro, M.A., and Waldor, M.K. (2009) D-amino acids govern stationary phase cell wall remodeling in bacteria. Science 325:1552-1555.

Lauretta, D.S., Balram-Knutson, S.S., Bennett, C.A., Bos, B.J., Drouet d'Aubigny, C., Christensen, P.R., Church, E.C.A., DellaGiustina, D.N., Enos, H.L., Golish, D.R., Hamilton, V.E., Hergenrother, C.W., Howell, E.S., Kidd, J.N., Nolan, M.C., Reuter, D.C., Rizk, B., Simon, A.A., and the OSIRIS-REx Team (2018) OSIRIS-REx encounters Earth: Signatures of a habitable world [abstract 1240]. In 49th Lunar and Planetary Science Conference, Lunar and Planetary Institute, Houston.

Lederberg, J. (1960) Exobiology: approaches to life beyond the Earth. Science 132:393-400.

Lepland, A., van Zuilen, M.A., Arrhenius, G., Whitehouse, M.J., and Fedo, C.M. (2005) Questioning the evidence for Earth's earliest life-Akilia revisited. Geology 33:77-79.

Levin, G.V. (2015) The curiousness of Curiosity. Astrobiology 15:101-103.

Levin, G.V. and Straat, P.A. (1977) Recent results from the Viking labeled release experiment on Mars. J Geophys Res 82:4663-4667.

Levin, G.V. and Straat, P.A. (2016) The case for extant life on Mars and its possible detection by the Viking Labeled Release experiment. Astrobiology 16:798-810.

Ljungdahl, L.G. and Wood, H.G. (1969) Total synthesis of acetate from $\mathrm{CO}_{2}$ by heterotrophic bacteria. Annu Rev Microbiol 23:515-538.

Lovelock, J.E. (1965) A physical basis for life detection experiments. Nature 207:568-570.

Lower, S.K., Hochella, M.F., and Beveridge, T.J. (2001) Bacterial recognition of mineral surfaces: nanoscale interactions between Shewanella and $\alpha-\mathrm{FeOOH}$. Science 292:1360-1363.

Luisi, P.L. (1998) About various definitions of life. Orig Life Evol Biosph 28:613-622.

Lunine, J.I., Waite, J.H., Postberg, F., Spilker, L., and Clark, K. (2015) Enceladus Life Finder: the search for life in a habitable moon [EGU2015-14923]. In Geophysical Research Abstracts, Vol. 17, EGU General Assembly. Available online at http://meetingorganizer.copernicus.org/EGU2015/EGU201514923.pdf

Marshall, S.M., Murray, A.R.G., and Cronin, L. (2017) A probabilistic calibrated framework for identifying biosignatures using Pathway Complexity. Philos Trans A Math Phys Eng Sci 375, doi:10.1098/rsta.2016.0342.

Martel, J., Young, D., Peng, H.H., Wu, C.Y., and Young, J.D. (2012) Biomimetic properties of minerals and the search for life in the martian meteorite ALH84001. Annu Rev Earth Planet Sci 40:167-193.

Martinez-Rodriguez, S., Martinez-Gomez, A.I., RodriguezVico, F., Clemente-Jimenez, J.M., and Las Heras-Vazquez, F.J. (2010) Natural occurrence and industrial applications of D-amino acids: an overview. Chem Biodivers 7:1531-1548.

Martins, Z., Botta, O., Fogel, M.L., Sephton, M.A., Glavin, D.P., Watson, J.S., Dworkin, J.P., Schwartz, A.W., and Ehrenfreund, P. (2008) Extraterrestrial nucleobases in the Murchison meteorite. Earth Planet Sci Lett 270:130-136.

Maskow, T. (2013) Calorimetry and biothermodynamics for biotechnology, medicine and environmental sciences: current status and advances. Engineering in Life Sciences 13: 508-509.

Mathis, C., Bhattacharya, T., and Walker, S.I. (2017) The emergence of life as a first-order phase transition. Astrobiology 17: 266-276.
McCollom, T.M. (2016) Abiotic methane formation during experimental serpentinization of olivine. Proc Natl Acad Sci USA 113:13965-13970.

McCubbin, F.M., Allton, J.H., Barnes, J.J., Boyce, J.W., Burton, A.S., Draper, D.S., Evans, C.A., Fries, M.D., Jones, J.H., Keller, L.P., Lawrence, S.J., Messenger, S.R., Ming, D.W., Morris, R.V., Nakamura-Messenger, K., Niles, P.B., Righter, K., Simon, J.I., Snead, C.J., Steele, A., Treiman, A.H., Vander Kaaden, K.E., Zeigler, R.A., Zolensky, M., and Stansbery, E.K. (2017) Priority science targets for future sample return missions within the Solar System out to the year 2050 [abstract 8224]. In Planetary Science Vision 2050 Workshop, Lunar and Planetary Institute, Houston, LPI Contribution 1989.

McDonald, G.D. and Storrie-Lombardi, M.C. (2006) Amino acid distribution in meteorites: diagenesis, extraction methods, and standard metrics in the search for extraterrestrial biosignatures. Astrobiology 6:17-33.

McKay, C.P. (2004) What is life-and how do we search for it in other worlds? PLoS Biol 2, doi:10.1371/journal.pbio.0020302.

McKay, C.P., Grunthaner, F.J., Lane, A.L., Herring, M., Bartman, R.K., Ksendzov, A., Manning, C.M., Lamb, J.L., Williams, R.M., Ricco, A.J., and Butler, M.A. (1998) The Mars Oxidant experiment (MOx) for Mars '96. Planet Space Sci 46:769-777.

McKay, C.P., Anbar, A.D., Porco, C., and Tsou, P. (2014) Follow the plume: the habitability of Enceladus. Astrobiology 14:352-355.

McKay, D.S., Gibson, E.K., Jr., Thomas-Keprta, K.L., and Vali, H. (1996) Search for past life on Mars: possible relic biogenic activity in martian meteorite ALH84001. Science 273:924-930.

Meadows, V. and Seager, S. (2010) Terrestrial planet atmospheres and biosignatures. In Exoplanets, edited by S. Seager, University of Arizona Press, Tucson, pp 441-470.

Meadows, V., Schwieterman, E., Arney, G., Lustig-Yaeger, J., Lincowski, A., Robinson, T.D., and Deming, D. (2016) What we could learn from observations of terrestrial exoplanets [id.122.12]. In American Astronomical Society, DPS meeting \#48, American Astronomical Society, Washington, DC.

Meierhenrich, U.J., Caro, G.M.M., Bredehöft, J.H., Jessberger, E.K., and Thiemann, W.H.-P. (2004) Identification of diamino acids in the Murchison meteorite. Proc Natl Acad Sci USA 101:9182-9186.

Meltzer, M. (2011) When Biospheres Collide. A History of NASA's Planetary Protection Programs, NASA SP-20114234, NASA, Washington, DC.

MEPAG Next Decade Science Analysis Group. (2008) Science priorities for Mars sample return. Astrobiology 8:489-535.

Meslin, P.-Y., Gasnault, O., Forni, O., Schröder, S., Cousin, A., Berger, G., Clegg, S.M., Lasue, J., Maurice, S., Sautter, V., Le Mouélic, S., Wiens, R.C., Fabre, C., Goetz, W., Bish, D., Mangold, N., Ehlmann, B., Lanza, N., Harri, A.-M., Anderson, R., Rampe, E., McConnochie, T.H., Pinet, P., Blaney, D., Léveillé, R., Archer, D., Barraclough, B., Bender, S., Blake, D., Blank, J.G., Bridges, N., Clark, B.C., DeFlores, L., Delapp, D., Dromart, G., Dyar, M.D., Fisk, M., Gondet, B., Grotzinger, J., Herkenhoff, K., Johnson, J., Lacour, J.-L., Langevin, Y., Leshin, L., Lewin, E., Madsen, M.B., Melikechi, N., Mezzacappa, A., Mischna, M.A., Moores, J.E., Newsom, H., Ollila, A., Perez, R., Renno, N., Sirven, J.-B., Tokar, R., de la Torre, M., d'Uston, L., Vaniman, D., Yingst, A., and the MSL Science Team. (2013) Soil diversity and hydration as observed by ChemCam at Gale Crater, Mars. Science 341, doi:10.1126/science. 1238670.

Mikucki, J.A., Pearson, A., Johnston, D.T., Turchyn, A.V., Farquhar, J., Schrag, D.P., Anbar, A.D., Priscu, J.C., and Lee, 
P.A. (2009) A contemporary microbially maintained subglacial ferrous “ocean." Science 324:397-400.

Moazeni, F., Zhang, G., and Sun, H.J. (2010) Imperfect asymmetry of life: Earth microbial communities prefer D-lactate but can use L-lactate also. Astrobiology 10:397-402.

Mojzsis, S.J., Arrhenius, G., McKeegan, K.D., Harrison, T.M., Nutman, A.P., and Friend, C.R.L. (1996) Evidence for life on Earth before 3,800 million years ago. Nature 384:55-59.

Monroe, A.A., Glein, C.R., Anbar, A.D., Shock, E.L., and Lunine, J.I. (2017) Amino acid destruction considerations for in situ measurements of Enceladus and other ocean worlds [abstract 3319]. In Astrobiology Science Conference 2017, Lunar and Planetary Institute, Houston, LPI Contribution 1965.

Mumma, M.J., Villanueva, G.L., Novak, R.E., Hewagama, T., Bonev, B.P., DiSanti, M.A., Mandell, A.M., and Smith, M.D. (2009) Strong release of methane on Mars in northern summer 2003. Science 323:1041-1045.

Mustard, J.F., Adler, M., Allwood, A., Bass, D.S., Beaty, D.W., Bell, J.F., Brinckerhoff, W.B., Carr, M., Des Marais, D.J., Drake, B., Edgett, K.S., Eigenbrode, J., Elkins-Tanton, L.T., Grant, J.A., Milkovich, S.M., Ming, D., Moore, C., Murchie, S., Onstott, T.C., Ruff, S.W., Sephton, M.A., Steele, A., and Treiman, A. (2013) Report of the Mars 2020 Science Definition Team, posted July, 2013, by the Mars Exploration Program Analysis Group. Available online at http://mepag.jpl.nasa.gov/ reports/MEP/Mars_2020_SDT_Report_Final.pdf

Nagy, B. (1966) A study of the optical rotation of lipids extracted from soils, sediments, and the Orgueil carbonaceous meteorite. Proc Natl Acad Sci USA 56:389-398.

National Research Council. (2007) The Limits of Organic Life in Planetary Systems, National Academies Press, Washington, DC.

National Research Council. (2010) New Worlds, New Horizons in Astronomy and Astrophysics, National Academies Press, Washington, DC.

National Research Council. (2011) Vision and Voyages for Planetary Science in the Decade 2013-2022, National Academies Press, Washington, DC.

Navarro-González, R. and McKay, C.P. (2011) Reply to comment by Biemann and Bada on "Reanalysis of the Viking results suggests perchlorate and organics at midlatitudes on Mars." J Geophys Res: Planets 116, doi:10.1029/2011JE003880.

Nealson, K.H. and Cox, B.L. (2002) Microbial metal-ion reduction and Mars: extraterrestrial expectations? Curr Opin Microbiol 5:296-300.

Neveu, M., Poret-Peterson, A.T., Anbar, A.D., and Elser, J.J. (2016) Ordinary stoichiometry of extraordinary microorganisms. Geobiology 14:33-53.

Newton, J.W. (1970) Metabolism of D-alanine in Rhodospirillum rubrum and its bacilliform mutants. Nature 228:1100-1101.

Noffke, N. (2015) Ancient sedimentary structures in the $<3.7$ Ga Gillespie Lake Member, Mars, that resemble macroscopic morphology, spatial associations, and temporal succession in terrestrial microbialites. Astrobiology 15:169-192.

Novoselov, A.A., Silva, D., Schneider, J., Abrevaya, X.C., Chaffin, M.S., Serrano, P., Navarro, M.S., Conti, M.J., and de Souza Filho, C.R. (2017) Geochemical constraints on the Hadean environment from mineral fingerprints of prokaryotes. Sci Rep 7, doi:10.1038/s41598-017-04161-2.

Oehler, D.Z. and Cady, S.L. (2014) Biogenicity and syngeneity of organic matter in ancient sedimentary rocks: recent advances in the search for evidence of past life. Challenges 5: 260-283.

Oehler, D.Z. and Etiope, G. (2017) Methane seepage on Mars: where to look and why. Astrobiology 17:1233-1264.
Owen, T. (1980) The search for early forms of life in other planetary systems: future possibilities afforded by spectroscopic techniques. In Strategies for the Search for Life in the Universe, edited by M.D. Papagiannis, Springer, Dordrecht, the Netherlands, pp 177-185.

Oyama, V.I. (1972) The Gas Exchange experiment for life detection: the Viking Mars lander. Icarus 16:167-184.

Oyama, V.I. and Berdahl, B.J. (1977) The Viking Gas Exchange experiment results from Chryse and Utopia surface samples. J Geophys Res 82:4669-4676.

Oyama, V.I., Berdahl, B.J., Carle, G.C., Lehwalt, M.E., and Ginoza, H.S. (1976) The search for life on Mars: Viking 1976 gas changes as indicators of biological activity. Orig Life Evol Biosph 7:313-333.

Pepe, M.S., Etzioni, R., Feng, Z., Potter, J.D., Thompson, M.L., Thornquist, M., Winget, M., and Yasui, Y. (2001) Phases of biomarker development for early detection of cancer. J Natl Cancer Inst 93:1054-1061.

Petit, J.R., Jouzel, J., Raynaud, D., Barkov, N.I., Barnola, J.M., Basile, I., Bender, M., Chappellaz, J., Davis, M., Delaygue, G., Delmotte, M., Kotlyakov, V.M., Legrand, M., Lipenkov, V.Y., Lorius, C., Pépin, L., Ritz, C., Saltzman, E., and Stievenard, M. (1999) Climate and atmospheric history of the past 420,000 years from the Vostok ice core, Antarctica. Nature 399:429-436.

Pizzarello, S. (2016) Molecular asymmetry in prebiotic chemistry: an account from meteorites. Life 6, doi:10.3390/life6020018.

Pizzarello, S. and Shock, E. (2010) The organic composition of carbonaceous meteorites: the evolutionary story ahead of biochemistry. Cold Spring Harb Perspect Biol 2, doi: 10.1101/cshperspect.a002105.

Prettyman, T.H., Yamashita, N., Toplis, M.J., McSween, H.Y., Schörghofer, N., Marchi, S., Feldman, W.C., Castillo-Rogez, J., Forni, O., Lawrence, D.J., Ammannito, E., Ehlmann, B.L., Sizemore, H.G., Joy, S.P., Polanskey, C.A., Rayman, M.D., Raymond, C.A., and Russell, C.T. (2017) Extensive water ice within Ceres' aqueously altered regolith: evidence from nuclear spectroscopy. Science 355:55-59.

Priscu, J.C., Adams, E.E., Lyons, W.B., Voytek, M.A., Mogk, D.W., Brown, R.L., McKay, C.P., Takacs, C.D., Welch, K.A., Wolf, C.F., Kirshtein, J.D., and Avci, R. (1999) Geomicrobiology of subglacial ice above Lake Vostok, Antarctica. Science 286:2141-2144.

Pross, A. (2011) Toward a general theory of evolution: extending Darwinian theory to inanimate matter. J Syst Chem 2, doi:10.1186/1759-2208-2-1.

Quinn, R.C., Martucci, H.F.H., Miller, S.R., Bryson, C.E., Grunthaner, F.J., and Grunthaner, P.J. (2013) Perchlorate radiolysis on Mars and the origin of martian soil reactivity. Astrobiology 13:515-520.

Radzicka, A. and Wolfenden, R. (1996) Rates of uncatalyzed peptide bond hydrolysis in neutral solution and the transition state affinities of proteases. J Am Chem Soc 118:6105-6109.

Rasmussen, B., Fletcher, I.R., Brocks, J.J., and Kilburn, M.R. (2008) Reassessing the first appearance of eukaryotes and cyanobacteria. Nature 455:1101-1104.

Reh, K., Spilker, L., Lunine, J.I., Waite, J.H., Cable, M.L., Postberg, F., and Clark, K. (2016) Enceladus Life Finder: the search for life in a habitable Moon. In 2016 IEEE Aerospace Conference Abstracts, IEEE, Piscataway, NJ, doi:10.1109/ AERO.2016.7500813

Reinbothe, S., Reinbothe, C., Apel, K., and Lebedev, N. (1996) Evolution of chlorophyll biosynthesis - the challenge to survive photooxidation. Cell 86:703-705. 
Reinhard, C.T., Olson, S.L., Schwieterman, E.W., and Lyons, T.W. (2017) False negatives for remote life detection on ocean-bearing planets: lessons from the early Earth. Astrobiology 17:287-297.

Rienstra, C.M., Hohwy, M., Hong, M., and Griffin, R.G. (2000) $2 \mathrm{D}$ and $3 \mathrm{D}{ }^{15} \mathrm{~N}-{ }^{13} \mathrm{C}-{ }^{13} \mathrm{C}$ NMR chemical shift correlation spectroscopy of solids: assignment of MAS spectra of peptides. J Am Chem Soc 122:10979-10990.

Sagan, C., Thompson, W.R., Carlson, R., Gurnett, D., and Hord, C. (1993) A search for life on Earth from the Galileo spacecraft. Nature 365:715-721.

Schneider, J., Léger, A., Fridlund, M., White, G.J., Eiroa, C., Henning, T., Herbst, T., Lammer, H., Liseau, R., Paresce, F., Penny, A., Quirrenbach, A., Röttgering, H., Selsis, F., Beichman, C., Danchi, W., Kaltenegger, L., Lunine, J.I., Stam, D., and Tinetti, G. (2010) The far future of exoplanet direct characterization. Astrobiology 10:121-126.

Schopf, J.W. (1993) Microfossils of the Early Archean Apex chert: new evidence of the antiquity of life. Science 260:640-646.

Schopf, J.W. and Kudryavtsev, A.B. (2012) Biogenicity of Earth's earliest fossils: a resolution of the controversy. Gondwana Res 22:761-771.

Schopf, J.W., Kudryavtsev, A.B., Agresti, D.G., Wdowiak, T.J., and Czaja, A.D. (2002) Laser-Raman imagery of Earth's earliest fossils. Nature 416:73-76.

Schrenk, M.O., Kelley, D.S., Delaney, J.R., and Baross, J.A. (2003) Incidence and diversity of microorganisms within the walls of an active deep-sea sulfide chimney. Appl Environ Microbiol 69:3580-3592.

Seager, S. and Bains, W. (2015) The search for signs of life on exoplanets at the interface of chemistry and planetary science. Sci Adv 1, doi:10.1126/sciadv.1500047.

Seager, S., Turner, E.L., Schafer, J., and Ford, E.B. (2005) Vegetation's red edge: a possible spectroscopic biosignature of extraterrestrial plants. Astrobiology 5:372-390.

Seager, S., Schrenk, M., and Bains, W. (2012) An astrophysical view of Earth-based metabolic biosignature gases. Astrobiology 12:61-82.

Sharp, Z. (2007) Principles of Stable Isotope Geochemistry, Pearson, Upper Saddle River, NJ.

Siegert, M.J., Tranter, M., Ellis-Evans, J.C., Priscu, J.C., and Berry Lyons, W. (2003) The hydrochemistry of Lake Vostok and the potential for life in Antarctic subglacial lakes. Hydrol Process 17:795-814.

Spencer, J.R. and Niebur, C. (2010) Planetary Science Decadal Survey Titan Saturn System Mission Concept Study Final Report. Available online at https://sites.nationalacademies .org/cs/groups/ssbsite/documents/webpage/ssb_059317.pdf

Steele, A., Goddard, D., Beech, I.B., Tapper, R.C., Stapleton, D., and Smith, J.R. (1998) Atomic force microscopy imaging of fragments from the martian meteorite ALH84001. $J$ Microsc 189:2-7.

Steele, A., Fries, M.D., Amundsen, H.E.F., Mysen, B.O., Fogel, M.L., Schweizer, M., and Boctor, N.Z. (2007) Comprehensive imaging and Raman spectroscopy of carbonate globules from martian meteorite ALH 84001 and a terrestrial analogue from Svalbard. Meteorit Planet Sci 42:1549-1566.

Steele, A., McCubbin, F.M., Fries, M., Kater, L., Boctor, N.Z., Fogel, M.L., Conrad, P.G., Glamoclija, M., Spencer, M., Morrow, A.L., Hammond, M.R., Zare, R.N., Vicenzi, E.P., Siljeström, S., Bowden, R., Herd, C.D.K., Mysen, B.O., Shirey, S.B., Amundsen, H.E.F., Treiman, A.H., Bullock, E.S., and Jull, A.J.T. (2012) A reduced organic carbon component in martian basalts. Science 337:212-215.
Steele, A., McCubbin, F.M., Benning, L., Siljestrom, S.S., Cody, G.D., Goreva, Y., Hauri, E.H., Wang, J., Kilcoyne, A.L.D., Grady, M.M., Smith, C., Freissinet, C., Glavin, D.P., Burton, A.S., Fries, M.D.F., Blanco, J.D.R., Glamoclija, M., Rogers, K.L., Mikhail, S., and Dworkin, J.P. (2013) Organic carbon inventory of the Tissint meteorite [abstract 2854]. In $44^{\text {th }}$ Lunar and Planetary Science Conference, Lunar and Planetary Institute, Houston.

Stern, J.C., Sutter, B., Jackson, W.A., Navarro-González, R., McKay, C.P., Ming, D.W., Archer, P.D. and Mahaffy, P.R. (2017) The nitrate/(per)chlorate relationship on Mars. Geophys Res Lett 44:2643-2651.

Stewart, E.J. (2012) Growing unculturable bacteria. J Bacteriol 194:4151-4160.

Storrie-Lombardi, M. and Nealson, K. (2003) Multivariate analysis of elemental chemistry as a robust biosignature [abstract \#13600]. In EGS-AGU-EUG Joint Assembly.

Summons, R.E., Jahnke, L.L., Hope, J.M., and Logan, G.A. (1999) 2-Methylhopanoids as biomarkers for cyanobacterial oxygenic photosynthesis. Nature 400:554-557.

Summons, R.E., Albrecht, P., McDonald, G., and Moldowan, J.M. (2008) Molecular biosignatures. Space Sci Rev 135:133-159.

Summons, R.E., Amend, J.P., Bish, D., Buick, R., Cody, G.D., Des Marais, D.J., Dromart, G., Eigenbrode, J.L., Knoll, A.H., and Sumner, D.Y. (2011) Preservation of martian organic and environmental records: final report of the Mars Biosignature Working Group. Astrobiology 11:157-181.

Summons, R.E., Sessions, A.L., Allwood, A.C., Barton, H.A., Beaty, D.W., Blakkolb, B., Canham, J., Clark, B.C., Dworkin, J.P., Lin, Y., Mathies, R., Milkovich, S.M., and Steele, A. (2014) Planning considerations related to the organic contamination of martian samples and implications for the Mars 2020 rover. Astrobiology 14:969-1027.

Szostak, J.W., Bartel, D.P., and Luisi, L. (2001) Synthesizing life. Nature 409:387-390.

ten Kate, I.L. (2010) Organics on Mars? Astrobiology 10: 589-603.

Tsapin, A., Goldfeld, M., and Nealson, K. (2002) Viking's experiments and hypothesis that $\mathrm{Fe}$ (VI) is a possible candidate as a martian oxidant. Icarus 159, doi:10.1006/icar.2002.6915.

Vago, J.L., Westall, F., Coates, A.J., Jaumann, R., Korablev, O., Ciarletti, V., Mitrofanov, I., Josset, J.-L., De Sanctis, M.C., Bibring, J.-P., Rull, F., Goesmann, F., Steininger, H., Goetz, W., Brinckerhoff, W., Szopa, C., Raulin, F., Edwards, H.G.M., Whyte, L.G., Fairén, A.G., Bridges, J., Hauber, E., Ori, G.G., Werner, S., Loizeau, D., Kuzmin, R.O., Williams, R.M.E., Flahaut, J., Forget, F., Rodionov, D., Svedhem, H., Sefton-Nash, E., Kminek, G., Lorenzoni, L., Joudrier, L., Mikhailov, V., Zashchirinskiy, A., Alexashkin, S., Calantropio, F., Merlo, A., Poulakis, P., Witasse, O., Bayle, O., Bayón, S., Meierhenrich, U., Carter, J., García-Ruiz, J.M., Baglioni, P., Haldemann, A., Ball, A.J., Debus, A., Lindner, R., Haessig, F., Monteiro, D., Trautner, R., Voland, C., Rebeyre, P., Goulty, D., Didot, F., Durrant, S., Zekri, E., Koschny, D., Toni, A., Visentin, G., Zwick, M., van Winnendael, M., Azkarate, M., Carreau, C., and the ExoMars Project Team. (2017) Habitability on early Mars and the search for biosignatures with the ExoMars Rover. Astrobiology 17:471-510.

VanBommel, S.J., Gellert, R., Berger, J.A., Campbell, J.L., Thompson, L.M., Edgett, K.S., McBride, M.J., Minitti, M.E., Pradler, I., and Boyd, N.I. (2016) Deconvolution of distinct lithology chemistry through oversampling with the Mars Science Laboratory Alpha Particle X-Ray Spectrometer. Xray Spectrom 45:155-161. 
Vandaele, A.C., Neefs, E., Drummond, R., Thomas, I.R., Daerden, F., Lopez-Moreno, J.J., Rodriguez, J., Patel, M.R., Bellucci, G., Allen, M., Altieri, F., Bolsée, D., Clancy, T., Delanoye, S., Depiesse, C., Cloutis, E., Fedorova, A., Formisano, V., Funke, B., Fussen, D., Geminale, A., Gérard, J.-C., Giuranna, M., Ignatiev, M., Kaminski, J., Karatekin, O., Lefèvre, F., Lopez-Puertas, M., Lopez-Valverde, M., Mahieux, A., McConnell, J., Mumma, M., Neary, L., Renotte, E., Ristic, B., Robert, S., Smith, M., Trokhimovsky, S., Vander Auwera, J., Villanueva, G., Whiteway, J., Wilquet, V., Wolff, M., and the NOMAD Team. (2015) Science objectives and performances of NOMAD, a spectrometer suite for the ExoMars TGO mission. Planet Space Sci 119:233-249.

van Zullen, M.A., Lepland, A., and Arrhenius, G. (2002) Reassessing the evidence for the earliest traces of life. Nature 418:627-630.

Vartoukian, S.R., Palmer, R.M., and Wade, W.G. (2010) Strategies for culture of 'unculturable' bacteria. FEMS Microbiol Lett 309, doi:10.1111/j.1574-6968.2010.02000.x.

Waite, J.H., Lewis, W.S., Kasprzak, W.T., Anicich, V.G., Block, B.P., Cravens, T.E., Fletcher, G.G., Ip, W.-H., Luhmann, J.G., McNutt, R.L., Niemann, H.B., Parejko, J.K., Richards, J.E., Thorpe, R.L., Walter, E.M., and Yelle, R.V. (2004) The Cassini Ion and Neutral Mass Spectrometer (INMS) investigation. Space Sci Rev 114:113-231.

Waite, J.H., Lewis, W.S., Magee, B.A., Lunine, J.I., McKinnon, W.B., Glein, C.R., Mousis, O., Young, D.T., Brockwell, T., Westlake, J., Nguyen, M.-J., Teolis, B.D., Niemann, H.B., McNutt, R.L., Perry, M., and Ip, W.-H. (2009) Liquid water on Enceladus from observations of ammonia and ${ }^{40} \mathrm{Ar}$ in the plume. Nature 460:487-490.

Waite, J.H., Glein, C.R., Perryman, R.S., Teolis, B.D., Magee, B.A., Miller, G., Grimes, J., Perry, M.E., Miller, K.E., Bouquet, A., Lunine, J.I., Brockwell, T., and Bolton, S. (2017) Cassini finds molecular hydrogen in the Enceladus plume: evidence for hydrothermal processes. Science 356:155-159.

Webster, C.R., Mahaffy, P.R., Flesch, G.J., Niles, P.B., Jones, J.H., Leshin, L.A., Atreya, S.K., Stern, J.C., Christensen, L.E., Owen, T., Franz, H., Pepin, R.O., Steele, A., and the MSL Science Team. (2013) Isotope ratios of $\mathrm{H}, \mathrm{C}$, and $\mathrm{O}$ in $\mathrm{CO}_{2}$ and $\mathrm{H}_{2} \mathrm{O}$ of the martian atmosphere. Science 341:260-263.

Webster, C.R., Mahaffy, P.R, Atreya, S.K., Flesch, G.J., Mischna, M.A., Meslin, P.-Y., Farley, K.A., Conrad, P.G., Christensen, L.E., Pavlov, A.A., Martín-Torres, J., Zorzano, M.-P., McConnochie, T.H., Owen, T., Eigenbrode, J.L., Glavin, D.P., Steele, A., Malespin, C.A., Archer, P.D., Sutter, B., Coll, P., Freissinet, C., McKay, C.P., Moores, J.E., Schwenzer, S.P., Bridges, J.C., Navarro-González, R., Gellert, R., Lemmon, M.T., and the MSL Science Team. (2015) Mars methane detection and variability at Gale Crater. Science 347:415-417.

Westall, F. and Cavalazzi, B. (2011) Biosignatures in rocks. In Encyclopedia of Geobiology, edited by J. Reitner and V. Thiel, Springer, Dordrecht, the Netherlands, pp 189-201.

Westall, F., Cavalazzi, B., Lemelle, L., Marrocchi, Y., Rouzaud, J.N., Simionovici, A., Salomé, M., Mostefaoui, S., Andreazza, C., Foucher, F., Toporski, J., Jauss, A., Thiel, V., Southam, G., MacLean, L., Wirick, S., Hofmann, A., Meiborn, A., Robert, F., and Défarge, C. (2011) Implications of in situ calcification for photosynthesis in a $\sim 3.3$ Ga-old microbial biofilm from the Barberton greenstone belt, South Africa. Earth Planet Sci Lett 310:468-479.

Westall, F., Foucher, F., Bost, N., Bertrand, M., Loizeau, D., Vago, J.L., Kminek, G., Gaboyer, F., Campbell, K.A., Bréhéret, J.G., Gautret, P., and Cockell, C.S. (2015) Bio- signatures on Mars: what, where, and how? Implications for the search for martian life. Astrobiology 15:998-1029.

Woese, C.R., Kandler, O., and Wheelis, M.L. (1990) Towards a natural system of organisms: proposal for the domains Archaea, Bacteria, and Eucarya. Proc Natl Acad Sci USA 87:4576-4579. Wolfe-Simon, F., Blum, J.S., Kulp, T.R., Gordon, G.W., Hoeft, S.E., Pett-Ridge, J., Stolz, J.F., Webb, S.M., Weber, P.K., Davies, P.C., Anbar, A.D., and Oremland, R.S. (2011) A bacterium that can grow by using arsenic instead of phosphorus. Science 332:1163-1166.

Young, E.D., Kohl, I.E., Sherwood Lollar, B., Etiope, G., Rumble, D., Li, S., Haghnegahdar, M.A., Schauble, E.A., McCain, K.A., Foustoukos, D.I., and Sutclife, C. (2017) The relative abundances of resolved ${ }^{12} \mathrm{CH}_{2} \mathrm{D}_{2}$ and ${ }^{13} \mathrm{CH}_{3} \mathrm{D}$ and mechanisms controlling isotopic bond ordering in abiotic and biotic methane gases. Geochim Cosmochim Acta 203:235-264.

Zahnle, K. (2015) Play it again, SAM. Science 347:370-371.

Zahnle, K., Freedman, R.S., and Catling, D.C. (2011) Is there methane on Mars? Icarus 212:493-503.

Zent, A.P. and McKay, C.P. (1994) The chemical reactivity of the martian soil and implications for future missions. Icarus 108:146-157.

Zhang, G. and Sun, H.J. (2014) Racemization in reverse: evidence that D-amino acid toxicity on Earth is controlled by bacteria with racemases. PLoS One 9, doi:10.1371/journal.pone.0092101.

Zhou, Z.Y., Shi, G.Q., Fontaine, R., Wei, K., Feng, T., Wang, F., Wang, G.Q., Qu, Y., Li, Z.H., Dong, Z.J., and Zhu, H.J. (2012) Evidence for the natural toxins from the mushroom Trogia venenata as a cause of sudden unexpected death in Yunnan Province, China. Angew Chem Int Ed Engl 51:2368-2370.

Address correspondence to: Marc Neveu 300 E St SW

Washington, DC 20546

E-mail: marc.f.neveu@nasa.gov

Submitted 6 October 2017

Accepted 23 March 2018 Associate Editor: Christopher McKay

$\begin{aligned} & \text { Abbreviations Used } \\ \mathrm{ATP} & =\text { adenosine triphosphate } \\ \mathrm{EDS} & =\text { energy dispersive spectroscopy } \\ \mathrm{GC}-\mathrm{MS} & =\text { gas chromatograph-mass spectrometer } \\ \mathrm{GEx} & =\text { Gas Exchange } \\ \mathrm{HPLC} & =\text { high-performance liquid chromatography } \\ \mathrm{LOD} & =\text { limit of detection } \\ \mathrm{LoQ} & =\text { limit of quantitation } \\ \mathrm{LR} & =\text { Labeled Release } \\ \mu \mathrm{L}^{2}-\mathrm{MS} & =\text { microprobe two-step laser mass spectrometry } \\ \mathrm{MOMA} & =\text { Mars Organic Molecule Analyzer } \\ \mathrm{MSL} & =\text { Mars Science Laboratory } \\ \mathrm{PAHs} & =\text { polycyclic aromatic hydrocarbons } \\ \mathrm{PCR} & =\text { polymerase chain reaction } \\ \mathrm{PR} & =\text { Pyrolitic Release } \\ \mathrm{RLS} & =\text { Raman Laser Spectrometer } \\ \mathrm{SEM} & =\text { scanning electron microscopy } \\ \mathrm{TEM} & =\text { transmission electron microscopy } \\ \mathrm{T}-\mathrm{RFLP} & =\text { terminal restriction fragment length } \\ & \text { polymorphism }\end{aligned}$

